\title{
Catalytic Activation of Bioorthogonal Chemistry with Light (CABL) Enables Rapid, Spatiotemporally-controlled Labeling and No-Wash, Subcellular 3D-Patterning in Live Cells using Long Wavelength Light
}

\author{
Andrew Jemas, ${ }^{1}$ Yixin Xie, ${ }^{1}$ Jessica E. Pigga, ${ }^{1}$ J. L. Caplan, ${ }^{2}$ Christopher W. am Ende, ${ }^{3}$ Joseph M. Fox ${ }^{1}$ \\ ${ }^{1}$ Department of Chemistry and Biochemistry, University of Delaware, Newark, Delaware 19716, USA \\ ${ }^{2}$ Department of Plant and Soil Sciences and Delaware Biotechnology Institute, University of Delaware, Newark, DE 19716, \\ USA
}

${ }^{3}$ Pfizer Worldwide Research and Development, Eastern Point Road, Groton, Connecticut 06340, United States

\begin{abstract}
Described is the spatiotemporally controlled labeling and patterning of biomolecules in live cells through the catalytic activation of bioorthogonal chemistry with light, referred to as "CABL". Here, an unreactive dihydrotetrazine (DHTz) is photocatalytically oxidized in the intracellular environment by ambient $\mathrm{O}_{2}$ to produce a tetrazine that immediately reacts with a trans-cyclooctene (TCO) dienophile. 6-(2Pyridyl)-dihydrotetrazine-3-carboxamides were developed as stable, cell permeable DHTz reagents that upon oxidation produce the most reactive tetrazines ever used in live cells with Diels-Alder kinetics exceeding $k_{2} 10^{6} \mathrm{M}^{-1} \mathrm{~s}^{-1}$. CABL photocatalysts are based on fluorescein or silarhodamine dyes with activation at 470 or $660 \mathrm{~nm}$. Strategies for limiting extracellular production of singlet oxygen are described that increase the cytocompatibility of photocatalysis. The HaloTag self-labeling platform was used to introduce DHTz tags to proteins localized in the nucleus, mitochondria, actin or cytoplasm, and high-yielding subcellular activation and labeling with a TCO-fluorophore was demonstrated. CABL is light-dose dependent, and 2-photon excitation promotes CABL at the sub-organelle level to selectively pattern live cells under nowash conditions. CABL was also applied to spatially resolved live-cell labeling of an endogenous protein target by using TIRF microscopy to selectively activate intracellular monoacylglycerol lipase tagged with DHTz-labeled small molecule covalent inhibitor. Beyond spatiotemporally controlled labeling, CABL also improves the efficiency of 'ordinary' tetrazine ligations by rescuing the reactivity of commonly used 3-aryl-6methyltetrazine reporters that become partially reduced to DHTzs inside cells. The spatiotemporal control and fast rates of photoactivation and labeling of CABL should enable a range of biomolecular labeling applications in living systems.
\end{abstract}

The activation of chemical reactivity by light plays a central role in identifying and studying biological molecules in cellular context. ${ }^{1-}$

${ }^{3}$ Prominent among the various roles of photochemistry in chemical biology are tools for tracking the dynamics of biological molecules in living cells. ${ }^{4}$ For example, fluorescence recovery after photobleaching (FRAP) has long been used to study the movement of mobility of cellular molecules. ${ }^{5}$ FRAP and related techniques operate by photobleaching a subcellular region of interest and studying the migration and exchange of fluorescently labeled molecules into that region. As a complement to FRAP, photoactivatable proteins have emerged as tools for the direct study of subcellular molecules that become fluorescent in response to light. ${ }^{6}$ Here, recombinant proteins can be made fluorescent in real time in response to focused light. Related techniques based on photoconvertible ${ }^{7}$ and photoswitchable ${ }^{8}$ proteins offer additional options for the study of fusion proteins in living systems. As an alternative to techniques based on fluorescent proteins, small molecule probes have been advanced as alternatives to photoactivation in the cellular environment. ${ }^{9-16}$ Small molecule photoactivation has traditionally involved photochemical uncaging ${ }^{9-14}$ with more recent innovations using the Wolff rearrangement ${ }^{15}$ and photoprotonation. ${ }^{16}$ An advantage to small molecule fluorophores is that they are generally brighter and more stable than fluorescent proteins. ${ }^{17}$ Challenges for current small molecules systems include increasing photoactivation rate and/or extending to longer wavelengths to further augment cytocompatibility.
Bioorthogonal chemistry is a powerful method for selective and high-yielding covalent bond formation in living cells and organisms. ${ }^{18,19}$ Bioorthogonal chemistry is highly versatile and can be applied to essentially any biological molecule that can be adapted to incorporate small molecule chemical reporters, and as such has been used to label glycans, ${ }^{20}$ lipids, ${ }^{21}$ nucleic acids, ${ }^{22}$ and proteins ${ }^{23}$ engineered via enzymatic labeling, ${ }^{24}$ self-labeling ${ }^{25}$ or genetic code expansion. ${ }^{26}$ Chemical probes bearing bioorthogonal tags have been used to probe for targets in endogenous systems, ${ }^{27-29}$ and strategies for activity-based protein profiling ${ }^{30}$ typically rely on enrichment via bioorthogonal chemistry. Because of this remarkable generality, new methodology for bioorthogonal labeling holds the potential for broad applicability in biology and medicine.

Photoactivatible bioorthogonal chemistry is an alternative method for labeling biological molecules in response to light..$^{31,32}$ Initial examples included the photolysis of tetrazole and cyclopropenones to produce cycloaddition-reactive nitrile imines and cyclooctyne derivatives, respectively. ${ }^{33-35}$ Further examples include photochemically inducible analogs of the Staudinger ${ }^{36}$ and $\mathrm{CuAAC}^{37}$ reactions as well as cycloadditions involving azirines, ${ }^{38}$ benzyne ${ }^{39}$, diarylsydnones, ${ }^{40,41}$ quinones, ${ }^{42-45}$ o-napthaquinone methides ${ }^{46}, o$ quinodimethanes ${ }^{47,48}$ and trans-cycloheptene. ${ }^{49}$

Variations of tetrazine ligation - the bioorthogonal Diels-Alder reaction of tetrazines - have become increasingly important due to their exceptional kinetics with trans-cyclooctenes and other strained dienophiles. ${ }^{50-53}$ Tetrazine ligation has become an important tool for 

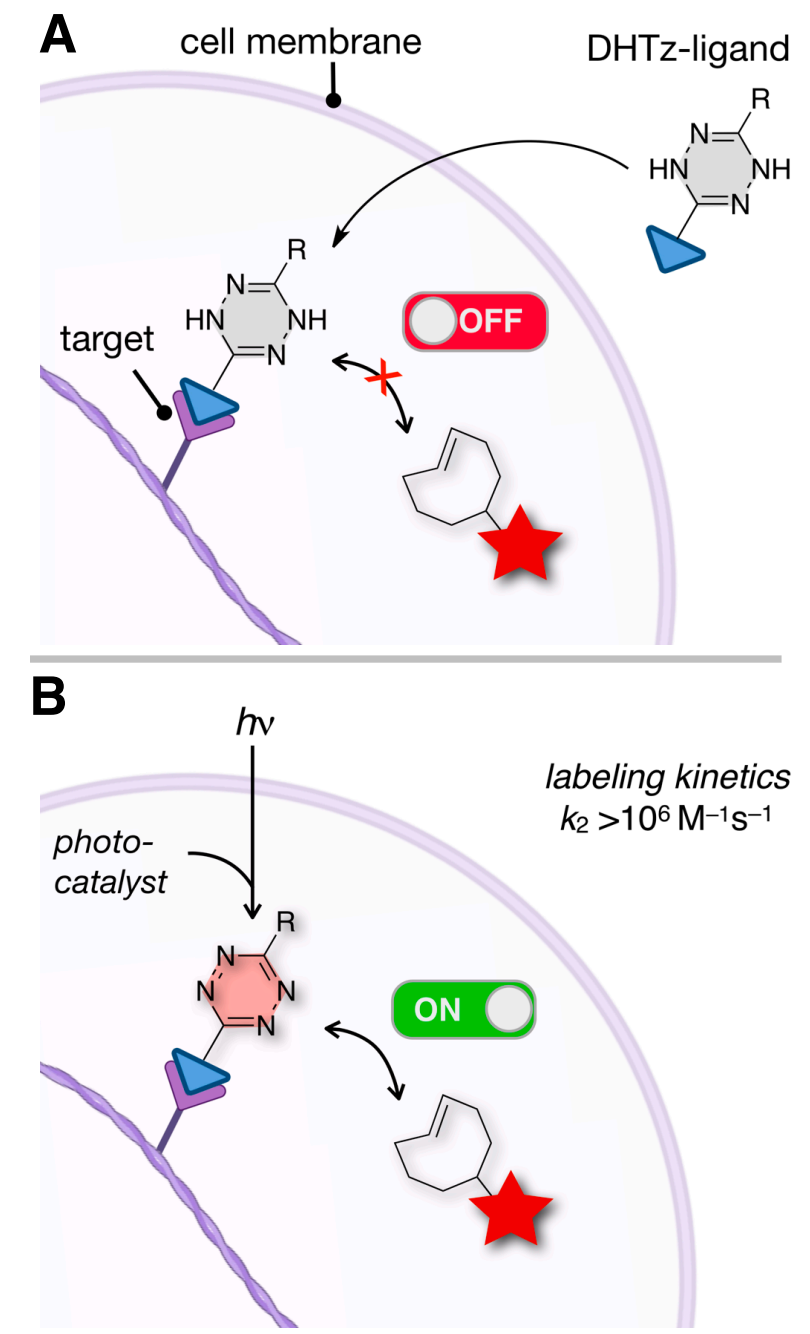

Fig 1. Illustration of spatiotemporally controlled subcellular labeling via catalytic activation of bioorthogonal chemistry with light, or "CABL". (A) Directing a DHTz-functionalized ligand to a subcellular target (illustrated here for actin) does not result in recruitment of a labeled TCO until (B) illumination in the presence of light results in the oxidation of DHTz to tetrazine, enabling rapid labeling via the fastest bioorthogonal reactions observed to date in live cells.

tagging bioorthogonal reporters in live cells for fluorescent and super-resolution microscopy. ${ }^{54-59}$ Photochemically inducible variants of tetrazine ligation have been described in recent years based on methods for uncaging cyclopropene ${ }^{60,61}$ and bicyclononyne ${ }^{62}$ dienophiles. Inducible versions of tetrazine ligation can also be achieved via the oxidation of dihydrotetrazine (DHTz) precursors ${ }^{63}$ with applications in electrochemically controlled bioconjugation at electrode surfaces, ${ }^{64}$ in batteries, ${ }^{65}$ and for colorimetric nitrous gas detection. ${ }^{66}$ In preprint, an $o$-nitrophenylphenyl protected dihydrotetrazine has been used with $405 \mathrm{~nm}$ light and without catalysis to uncage tetrazines that react with TCO with rates of $10^{2} \mathrm{M}^{-1} \mathrm{~s}^{-1} .{ }^{67}$

Oxidation-induced bioorthogonal chemistry has emerged as a powerful method for on-demand bioorthogonal chemistry. ${ }^{68}$ Previously, our group described activation of tetrazine ligation using catalytic stimuli, ${ }^{69}$ where either visible light and a photocatalyst or the enzyme horseradish peroxidase was used to catalyze the oxidation of a DHTz to a tetrazine. (Fig 1). Oxygen serves as the terminal oxidant in this process, and several photocatalysts were found to be effective including methylene blue which catalyzes photooxidation upon excitation by $660 \mathrm{~nm}$ light. This initial system for photocatalytic oxidation using red light had found several in vitro applications, ${ }^{69-72}$ but had limited use in live cell applications due to phototoxicity associated with the sensitization of singlet oxygen by methylene blue. More recently we have shown that silarhodamine $(\mathrm{SiR})$ dyes, initially developed as fluorophores for biological imaging, ${ }^{73-76}$ can be repurposed as photocatalysts for DHTz oxidation. ${ }^{77}$ The Janelia-SiR dyes $^{76}$ were found to be especially effective even at low catalyst loadings. With SiR-photocatalysts, DHTz oxidation is more rapid than the competing sensitization of singlet oxygen, and therefore the photocatalytic activation of tetrazine ligation can be applied to protein modification while minimizing oxidative damage. In the presence of live human prostate cancer cells, SiR-red light photocatalysis was used to crosslink polymers to create hydrogels and enable their culture in $3 \mathrm{D} .{ }^{77}$ This photoinducible hydrogel formation could also be carried out in vivo in live mice through subcutaneous injection of a solution containing SiR photocatalyst and a hydrogel precursor, followed by brief in vivo irradiation with $660 \mathrm{~nm}$ light to produce a stable hydrogel material. ${ }^{77}$ While these recent studies have demonstrated the ability to photocatalytically activate tetrazine ligation in the extracellular environment, the poor cellular permeability of the DHTz analogs used previously prevented us from exploring the potential for intracellular applications, and we had not explored spatiotemporal control of photoactivation at the cellular level.

Described herein is the spatiotemporally controlled labeling and patterning of biomolecules inside of live cells through the catalytic activation of bioorthogonal chemistry with light, referred to as "CABL". The new method is mechanistically different from traditional methods of photoactivation involving a chromophoric change upon irradiation. In CABL, a DHTz tag is directed to a subcellular target, where it is inactive in bioorthogonal conjugation chemistry. In the presence of a photocatalyst and light, the dormant $\mathrm{DHTz}$ is converted into a highly reactive tetrazine that can then undergo rapid bioorthogonal chemistry. (Fig 1). Key to the success of CABL in live cells is a new class of DHTz reagents that are cell permeable and stable in the intracellular environment. The fluorescent dyes, fluorescein (FL) and Janelia Si-Rhodamine, thienyl JF $\mathrm{JF}_{646}$ (SiR$\left.\mathbf{t J F}_{646}\right)^{76}$ (Fig 2A), serve as photocatalysts in conjunction with brief irradiation at $470 \mathrm{~nm}$ and $660 \mathrm{~nm}$, respectively, to produce the most reactive tetrazines ever used in live cells with Diels-Alder kinetics exceeding $k_{2} 10^{6} \mathrm{M}^{-1} \mathrm{~s}^{-1}$. CABL can be used to photoactivate covalent attachment via bioorthogonal chemistry on a variety of subcellular protein targets to deliver bright, stable small molecule fluorophores to illuminated regions. In conjunction with 2-photon excitation it is possible to selectively pattern subcellular structures in $3 \mathrm{D}$ with submicron spatial resolution with live imaging under no-wash conditions. Photoactivation by CABL is not limited to overexpressed proteins, and was also applied to spatially resolved live-cell labeling of the protein target monoacylglycerol lipase (MAGL) at low, endogenous cellular concentration.

\section{Results and Discussion}

\section{Synthesis and Evaluation of DHTz's with Improved Permea-} bility, Stability, and Reactivity

Essential to creating a system for photocatalysis in live cells was the development of 6-(2-pyridyl)-dihydrotetrazine-3-carboxamides $\mathbf{1}$ as a new class of compounds that display improved cell permeability and stability in the reduced DHTz state and enhanced reactivity 
in the oxidized tetrazine state (Fig 2A). Ethyl 6-pyridyl-DHTz-3carboxylate $\mathbf{6}$ was synthesized through the sequence outlined in Fig $2 \mathrm{~b}$ : hydrazide 3 and ethyl chlorooxoacetate were combined to give the unsymmetrical diacylhydrazine 4 , which was reacted with $\mathrm{PCl}_{5}$ to give dichloride 5. Condensation with a stoichiometric amount of anhydrous hydrazine in ethanol gave $\mathbf{6}$ on gram scale. ${ }^{78,79}$ DHTz ester $\mathbf{6}$ is reactive enough to directly form amides upon reaction with amines due to the electron withdrawing nature of the DHTz.

A

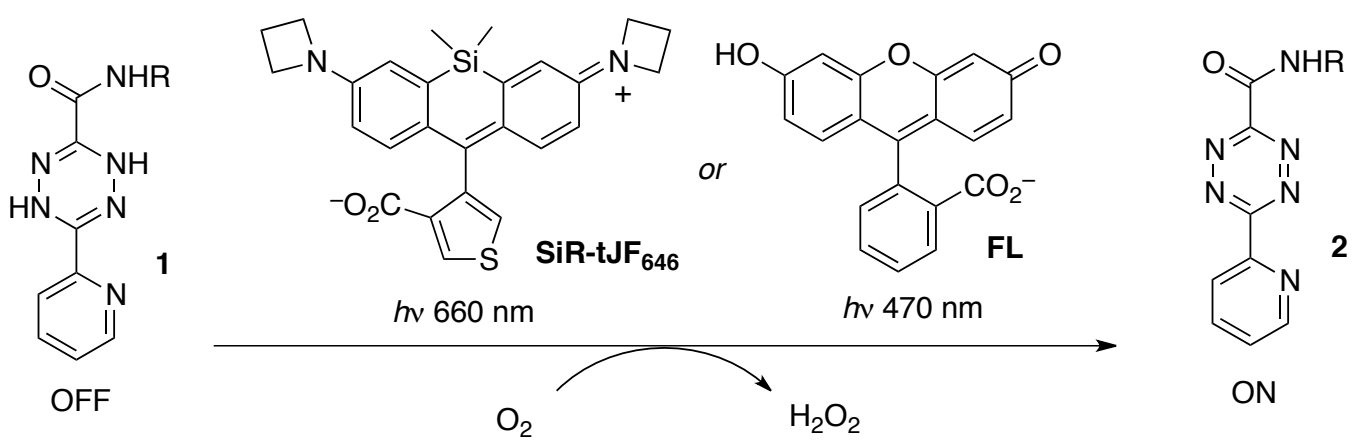

\section{B. Synthesis}<smiles>CCOC(=O)C(=O)[CH-]C(=O)NNC(=O)c1ccccn1</smiles><smiles>CCOC(=O)/C(Cl)=N/N=C(\Cl)c1ccccn1</smiles><smiles>CCOC(=O)C1=NNC(c2ccccn2)=NN1</smiles><smiles>CCCCNC(=O)C1=NNC(c2ccccn2)=NN1</smiles><smiles>O=C(C1=NNC(c2ccccn2)=NN1)N(CCO)CCO</smiles><smiles>O=C(NCCOCCOCCCCCCCl)C1=NNC(c2ccccn2)=NN1</smiles>

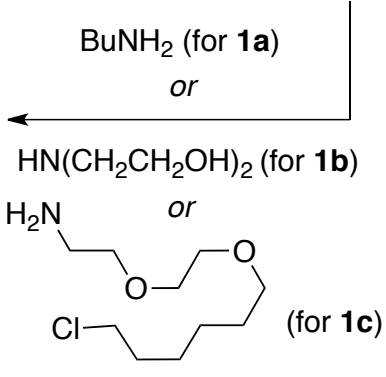

C. Relative reactivity of tetrazines toward eq. 5-OH-TCO

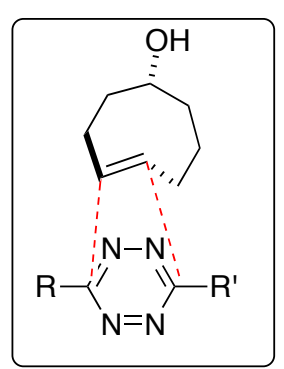<smiles>CCCCNC(=O)c1nnc(-c2ccccn2)nn1</smiles>

$2 a$<smiles>NS(=O)(=O)Cc1ccc(-c2nncnn2)cc1</smiles>

7<smiles></smiles>

1.0<smiles>Cc1nnc(-c2ccc(CN)cc2)nn1</smiles>

\section{Kinetics of $\mathbf{2 a}$ with TCO derivatives in PBS}
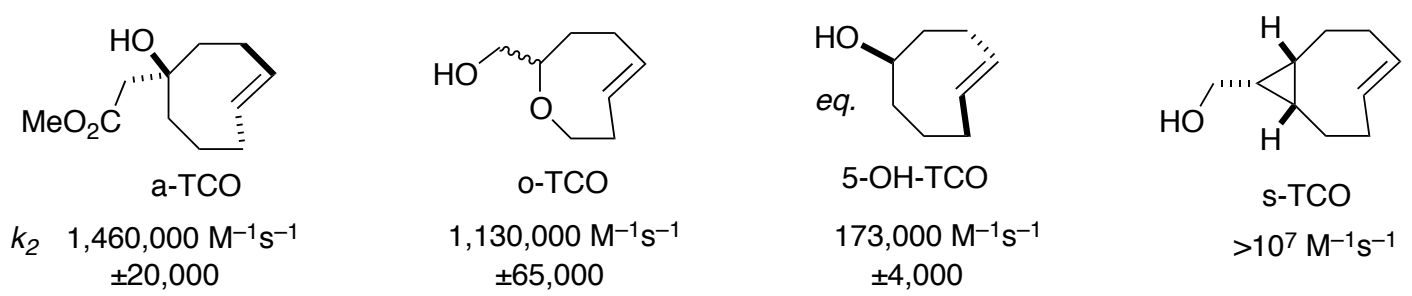

Fig 2. (A) Silarhodamine or fluorescein dyes catalyze the oxidation of dihydrotetrazine (DHTz) $\mathbf{1}$ by $\mathrm{O}_{2}$ to produce tetrazine $\mathbf{2}$. (B) Synthesis of amine-reactive DHTz 6 and amide analogs 1a-c. (C) Relative rate of tetrazine-TCO ligation for 2a vs other tetrazine derivatives in aqueous buffer. (D) Kinetics for reaction of $\mathbf{2 a}$ with TCO derivatives. 
A
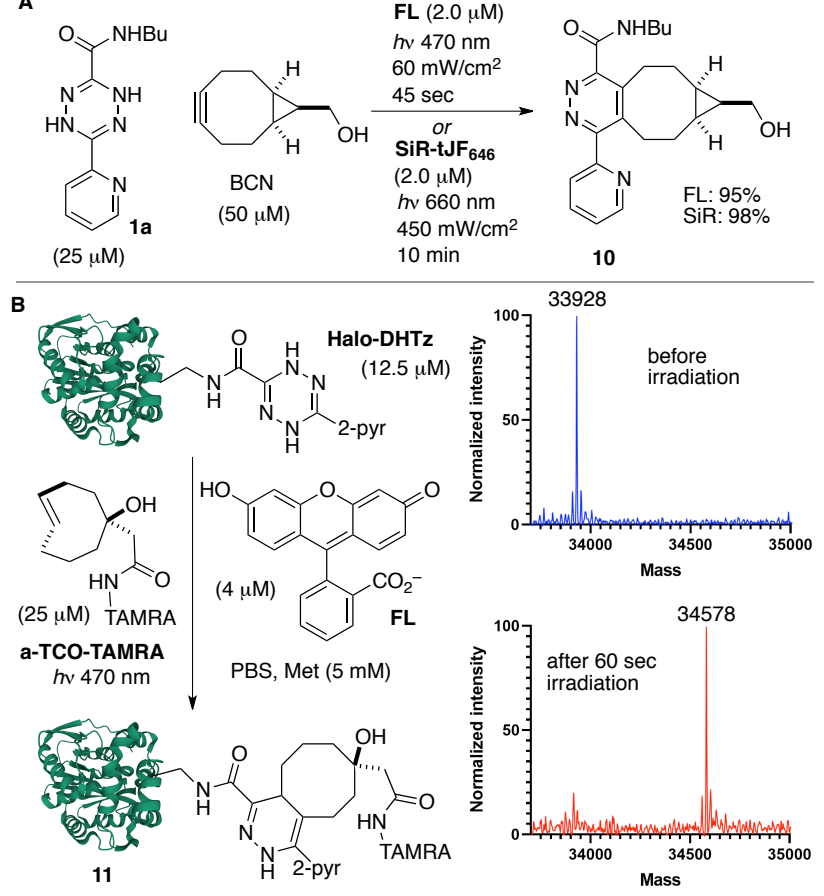

Fig 3 (A) DHTz oxidation/Diels-Alder reaction of 1a with BCN is photocatalyzed by either $\mathrm{SiR}$ or fluorescein gives conjugate $\mathbf{1 0}$. (B) Photocatalytic DHTz oxidation/Diels-Alder reaction of HaloDHTz in the presence of methionine, a singlet oxygen scavenger, produces conjugate $\mathbf{1 1}$.

Butylamine can undergo direct amidation directly with $\mathbf{6}$ to give amide $\mathbf{1 a}$. For the synthesis of secondary amide $\mathbf{1 b}$ and HaloTag-substrate $\mathbf{1 c}$, activation with trimethylaluminum ${ }^{80}$ was required to promote the amidation reaction (Figure 2B).

UV-vis and NMR spectroscopies were used to monitor the stability of DHTz derivatives in metal-free PBS-buffer, prepared by simply passing PBS through chelex resin. ${ }^{81}$ DHTz $1 a(40 \mu \mathrm{M})$ was shown by UV-vis to retain $96 \%$ and $94 \%$ of the DHTz oxidation state after $24 \mathrm{~h}$ and $49 \mathrm{~h}$, respectively (Fig S1). Similarly, DHTz $1 \mathbf{b}(25 \mathrm{mM})$ was shown by ${ }^{1} \mathrm{H}$ NMR to be $\geq 95 \%$ stable after $48 \mathrm{~h}$ in deuterated PBS (Fig S2). The stability of DHTz la was also studied in $10 \%$ human serum in PBS buffer; a UV-vis assay showed a $150 \mu \mathrm{M}$ solution of 1 a retained $92 \%, 81 \%$ and $71 \%$ DHTz oxidation state after $20 \mathrm{~h}, 2$ $\mathrm{d}$ and $3.5 \mathrm{~d}$ respectively (Fig S3). For cellular experiments, FBS was replaced with serum-free Opti-MEM minimal media prior to $\mathrm{DHTz}$ introduction.

Photooxidation of DHTz 1a generates tetrazine 2a which participates in the fastest bioorthogonal reactions measured to date. Tetrazine 2a was also prepared independently via chemical oxidation of 1a using phenyliodonium diacetate. ${ }^{63}$ Using stopped-flow kinetics with UV-vis monitoring, the rate of reactivity of eq-5-hydroxy-transcyclooctene (5-OH-TCO) toward 2a was compared to known tetrazines as shown in Fig 2C. Chosen for comparison were monoaryltetrazine $\mathbf{7}^{82}$ and dipyridyltetrazine $\mathbf{8},{ }^{63,83}$ which are commonly employed for their exceptional reactivity, and 3-methyl-6-aryltetrazine $9,^{82}$ which is commonly employed for its high stability. In PBS, the rate of $\mathbf{2 a}$ with 5-OH-TCO was measured to be $173,000 \mathrm{M}^{-}$ ${ }^{1} \mathrm{~s}^{-1}$, which is 7 -times and 10-times faster than analogous reactions of
5-OH-TCO toward 7 and $\mathbf{8}$, respectively. In $\mathrm{MeOH}$, tetrazine $\mathbf{2 a}$ is more than 300 times more reactive than $\mathbf{9}$. The rate constants for the reaction of tetrazine $\mathbf{2 a}$ toward other trans-cyclooctene dienophiles are displayed in Figure 2D. As expected, faster reactivity was observed with soluble a-TCO ${ }^{84}$ and o-TCO ${ }^{85}$ derivatives, which reacted with $2 \mathrm{a}$ in PBS with rates of $1.46 \times 10^{6} \mathrm{M}^{-1} \mathrm{~s}^{-1}$ and $1.13 \times 10^{6}$ $\mathrm{M}^{-1} \mathrm{~s}^{-1}$. Under aqueous conditions, the reaction with the conformationally strained alkene s-TCO ${ }^{50,86}$ was too rapid for us to measure using stopped flow spectroscopy $\left(>10^{7} \mathrm{M}^{-1} \mathrm{~s}^{-1}\right)$.

The hydrolytic stability of tetrazine $\mathbf{2 a}$ was studied by UV-vis spectroscopy by monitoring the disappearance of the signature tetrazine absorbance at $520 \mathrm{~nm}$. Tetrazine $\mathbf{2 a}$ has a hydrolysis half-life of $45 \mathrm{~min}$ in PBS at r.t. (Figure S4). However, any concerns about background reactivity are ameliorated by the 'on demand' nature of CABL as bioorthogonal reactions of $\mathbf{2 a}$ are much more rapid $\left(t_{1 / 2} \sim 1\right.$ sec for $1 \mu \mathrm{M} \mathrm{TCO}+1 \mu \mathrm{M}$ a-TCO) than background reactions. Thus, by activating tetrazine ligation in the presence of TCO dienophiles, CABL should not only provide spatiotemporal control but would also enable bioorthogonal reactions with exceptional rates.

Photocatalytic tetrazine ligation of 1a was initially demonstrated using BCN as the dienophile for in situ Diels-Alder reaction (Fig $3 \mathrm{~A})$. While BCN is less reactive than TCO in Diels-Alder chemistry, for small molecule characterization $\mathrm{BCN}$ conjugation has the advantage of producing a single aromatic product. As shown in Fig 3A, treatment of 1 a with $\mathrm{BCN}$ under photocatalytic conditions using FL $(2 \mu \mathrm{M})$ or SiR-tJF $_{646}(2 \mu \mathrm{M})$ produced conjugate 10 in $95-98 \%$ yield after irradiation at $470 \mathrm{~nm}$ and $660 \mathrm{~nm}$, respectively (Figs S8-9). UV-vis spectroscopy was used to monitor the photocatalyzed transformation of $\mathbf{1 a}(20 \mu \mathrm{M})$ to tetrazine $\mathbf{2 a}$ in the absence of $\mathrm{BCN}$ as a trapping agent.

Fluorescein (FL) is a particularly efficient photocatalyst for DHTz oxidation. ${ }^{69}$ Fluorescein has been used as an in vitro photocatalyst $^{87}$ and in cellular experiments to promote arylboronate ester oxidation via singlet oxygen sensitization. ${ }^{88}$ With $1 \mu \mathrm{M}$ FL and 470 $\mathrm{nM}$ light, the formation of $\mathbf{2 a}$ is light dependent and yield of $\mathbf{2 a}$ reached a maximum of $79 \%$ yield after $40 \mathrm{~s}$ (Fig S5), and then decreased upon prolonged irradiation by a degradation process that is also photocatalyzed (Fig S6). Similarly, an $80 \%$ yield of $\mathbf{2 a}$ was observed after $400 \mathrm{~s}$ with photocatalysis by $1 \mu \mathrm{M} \mathrm{SiR-tJF_{646 }}$ and 660 nM light (Fig S7).

Photocatalytic tetrazine ligation was also demonstrated with a protein-DHTz conjugate with reaction monitoring by mass spectrometry as shown in Figure 3B. The self-labeling HaloTag protein was labeled with the alkylchloride 1c to produce Halo-DHTz $(33,928 \mathrm{Da})$. As shown in Figure 3B, conjugation with a-TCOTAMRA took place efficiently upon irradiation at $470 \mathrm{~nm}$ in the presence of fluorescein as a photocatalyst to give conjugate 11 $(34,578 \mathrm{Da})$ while exposure to photocatalyst and a-TCO-TAMRA in the absence of light showed no change in mass. Under photocatalytic conditions, both FL and SiR can also sensitize the formation of singlet oxygen at a rate competitive with the photooxidation of DHTz 1. Methionine $(200 \mu \mathrm{M})$ was added as a singlet oxygen scavenger to limit protein oxidation and mimic the intracellular mechanisms for regulating singlet oxygen. As will be discussed below, strategies for limiting extracellular singlet oxygen production were developed and shown to maximize the efficacy of CABL in experiments in live cells. 
A

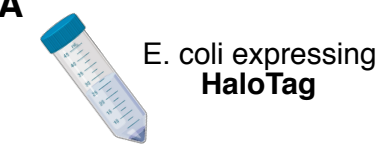

or

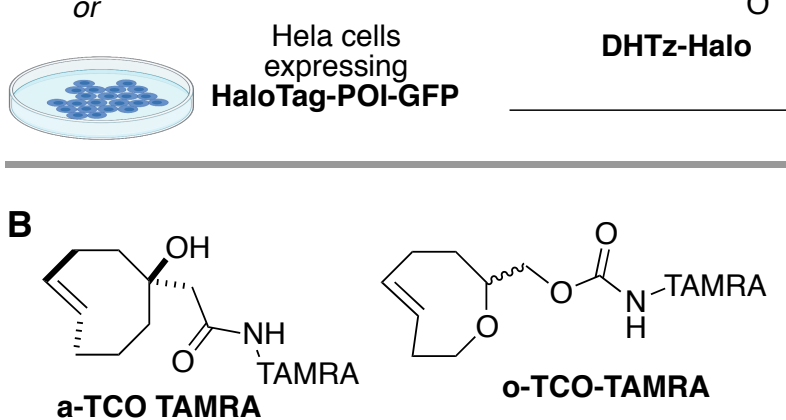<smiles>O=C(O)C1=NNC(C(=O)NC2(Cl)CCCCCCCOCC2)=NN1</smiles>

then wash
2)

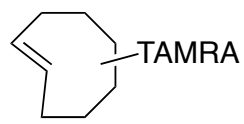

FL or FDA

SiR-tJF 646

$h v(470 \mathrm{~nm}) \quad h v(660 \mathrm{~nm})$

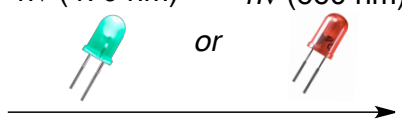

chase lyse, SDS-PAGE

C Intracellular Delivery of FL-photocatalyst<smiles>CC(=O)Oc1ccc2c(c1)Oc1cc(OC(C)=O)ccc1C21OC(=O)c2ccccc21</smiles>

FL

\section{Fluorescein photocatalysis}
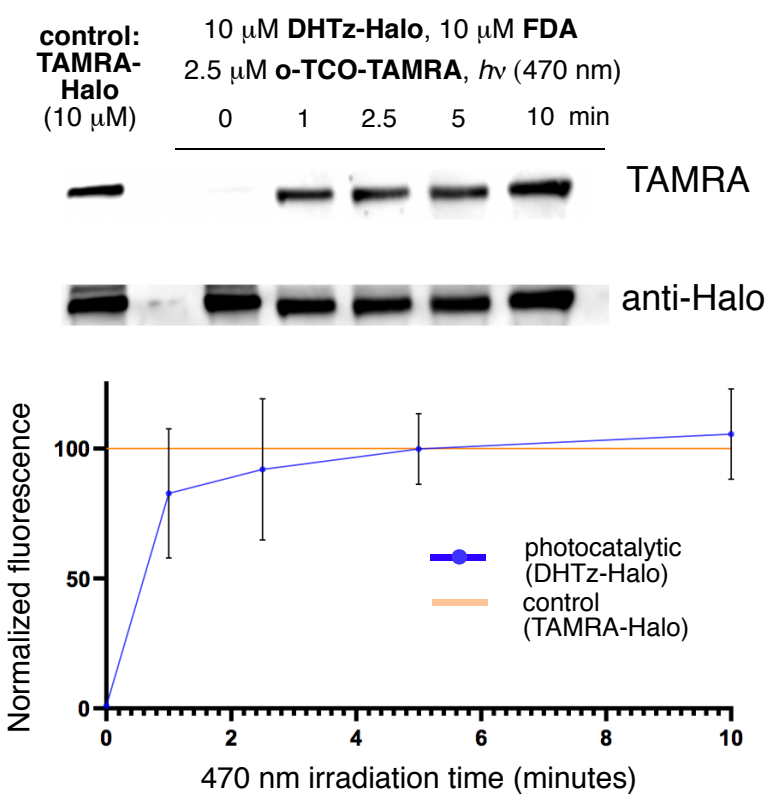

\section{E SiR photocatalysis}
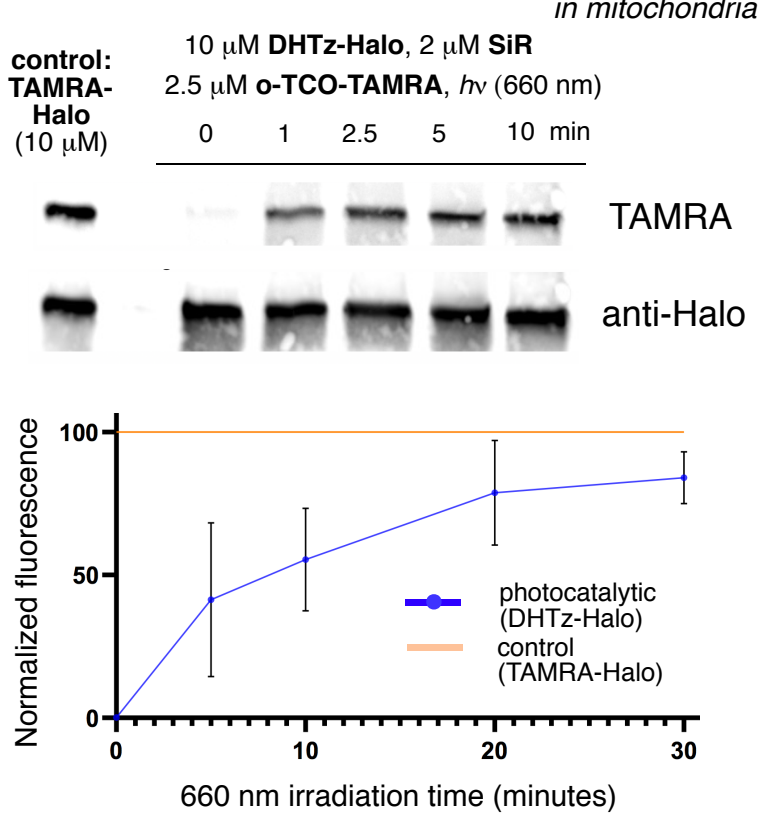

Fig 4 (A) Workflow for introducing DHTz labels to Halotag fusion proteins in HeLa cells or E. coli with subsequent fluorescent labeling via CABL. (B) Structure of TAMRA-TCO conjugates. (C) Upon hydrolysis by esterases, fluorescein diacetate becomes fluorescent and an active photocatalyst in live cells. (D, E) In-gel fluorescence was used to monitor the progress of subcellular photocatalysis using (D) Fluorescein/470 nm light $/ 60 \mathrm{~mW} / \mathrm{cm}^{2}$ and (E) SiR-tJF $646 / 660 \mathrm{~nm} / 450 \mathrm{~mW} / \mathrm{cm}^{2}$ light.

\section{Labeling Live Cells with CABL}

We next sought to demonstrate that CABL could be carried out in a variety of intracellular targets in live cells. To this end, the HaloTag self-labeling platform was used to introduce DHTz tags to a variety of mammalian subcellular targets as well as to live bacteria. As displayed in Fig 4, HeLa cells were transfected with a green fluorescent protein HaloTag-GFP construct fused to a 'protein of interest' (POI) that controls subcellular localization, and then labeled by the small molecule DHTz-HaloTag. Subsequently, cells are treated with a photocatalyst and either a-TCO-TAMRA or o-TCOTAMRA (Fig 4B) - fluorescent conjugates of TCO derivatives that were chosen for their hydrophilicity and improved permeability relative to traditional TCO derivatives. ${ }^{84}$ Upon irradiation, conjugation is expected only in those cells that express the HaloTag fusion protein, and analysis by SDS-PAGE with fluorescent imaging was used to provide a measure of conjugation efficiency. Unlike silarhodamine and fluorescein derivatives, TAMRA does not act as a photocatalyst for DHTz oxidation, and therefore functions only as a fluorescent reporter.

Fluorescein diacetate (FDA) was found to be superior to the direct use of fluorescein (FL). FDA is a cell permeable derivative of the 'closed-form' of FL. In live mammalian cells, esterases rapidly hydrolyze FDA to produce FL, which due to limited permeability becomes 'trapped' intracellularly, manifesting in intracellular green fluorescence (Fig 4C). Therefore, FDA has the advantage of delivering and concentrating FL within the intracellular environment and thereby increases the efficacy of localized photocatalysis. As shown 
in Fig 4D, HeLa cells expressing HaloTag-H2B-GFP (nucleus) tagged with DHTz-Halo $(10 \mu \mathrm{M})$, washed and then treated with oTCO-TAMRA $(2.5 \mu \mathrm{M})$ and FDA for $30 \mathrm{~min}$. Cells were then washed to remove excess unbound FDA and irradiated at $470 \mathrm{~nm}$ at $60 \mathrm{~mW} / \mathrm{cm}^{2}$ using an LED light source. Because the nascent FL tends to leak out of the cell after hydrolysis, irradiation was performed within 30 minutes of the washing step. All labeling experiments were carried out for a total of $10 \mathrm{~min}$ : after irradiation for the desired amount of time (0-10 min), the cells were kept in the dark for the balance of the $10 \mathrm{~min}$, at which point the TCO reagent was chased by a non-fluorescent tetrazine, and the cells were lysed and analyzed by SDS-PAGE. As shown in Fig 4D, fluorescent labeling increased with irradiation time, with $95 \%$ maximum labeling achieved after 5 minutes of illumination. As a qualitative measure of the degree of labeling efficiency, we directly labeled HeLa cells expressing HaloTag-H2B-GFP for 30 min with TAMRA-Halo (structure in Fig 5C): the degree of labeling by in-gel fluorescence was similar to that observed using CABL (Figs 4D and S19). Efficient light- dependent labeling was also observed in similar experiments where DHTz-Halo was targeted to mitochondria or cytosol and labeled with o-TCO-TAMRA under photocatalytic conditions using FDA and $470 \mathrm{~nm}$ light $\left(60 \mathrm{~mW} / \mathrm{cm}^{2}\right)$. In all cases maximum labeling was achieved within $10 \mathrm{~min}$. CABL was also efficient in E. coli expressing HaloTag that was tagged with DHTz-Halo and labeled with s-TCOTAMRA using SiR-tJF $\mathbf{6 4 6}_{\mathbf{6}}$ as the photocatalyst, with maximum labeling achieved within $10 \mathrm{~min}$ upon irradiation at $660 \mathrm{~nm}(60$ $\left.\mathrm{mW} / \mathrm{cm}^{2}\right)$ (Fig. S17).

As shown in Fig 4E, SiR-tJF 646 can be used as photocatalyst in conjunction with $660 \mathrm{~nm}$ light for CABL in live cells. Unlike FL, SiR-tJF $\mathbf{6 4 6}_{6}$ is membrane permeable and is not selectively delivered to the intracellular environment. Therefore, the dye can sensitize singlet oxygen in the extracellular environment where reactive oxygen species are not actively regulated by cellular mechanisms. Under the conditions used with FDA/470 nm, photocatalysis with SiR$\mathbf{t J F}_{646} / 660 \mathrm{~nm}$ led to cellular lysis, which we hypothesized was a result of oxidative stress due to the sensitization of ${ }^{1} \mathrm{O}_{2}$ in the

A
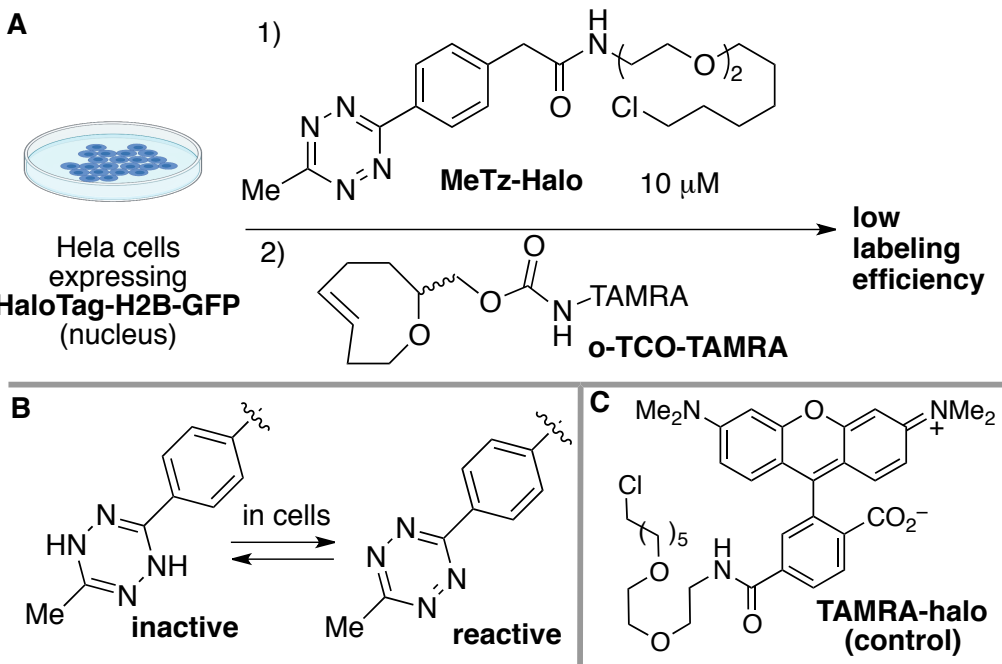

D<smiles>Cc1nnc(-c2ccc(CN)cc2)nn1</smiles>

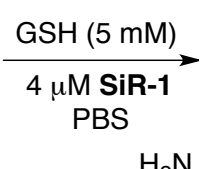

$\mathrm{H}_{2} \mathrm{~N}$<smiles>NCc1ccccc1</smiles><smiles>Cc1ccc(-c2ccn[nH]2)cc1</smiles>

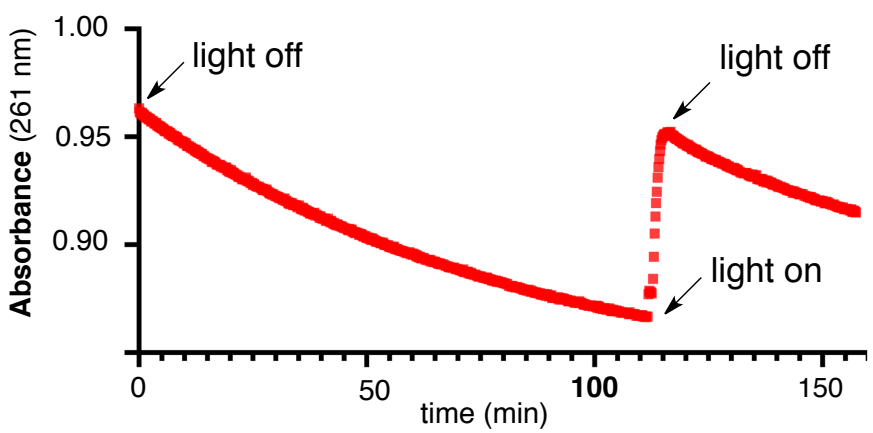

E

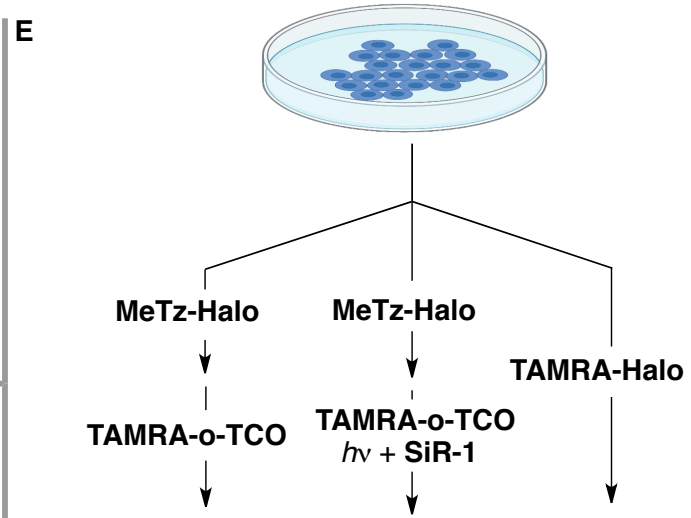

TAMRA

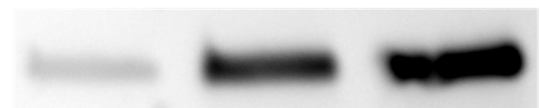

anti-Halo
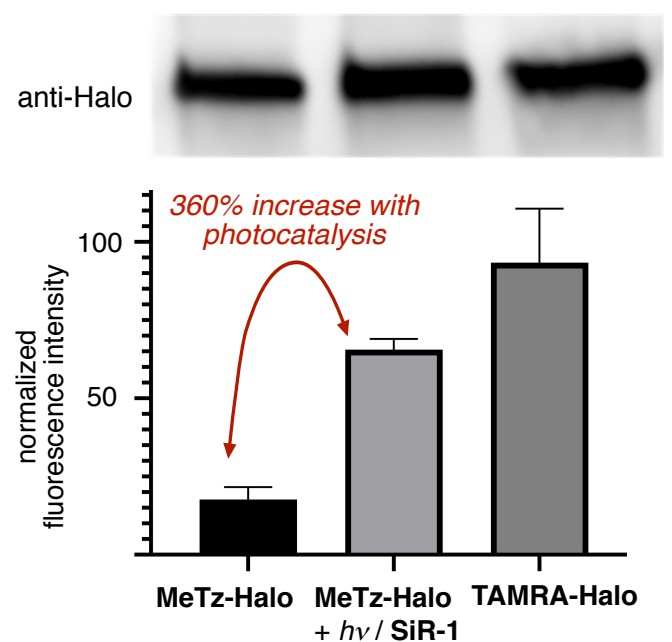

Fig 5. CABL improves the efficiency of a 'regular' bioorthogonal tetrazine ligation. (A) Intracellular labeling of a MeTzHalo-tagged protein proceeds with low labeling efficiency relative to direct labeling by a (C) TAMRA-halo control. (B) The low efficiency of the tetrazine ligation was hypothesized to be a result of inactivation of the tetrazine in the cellular environment. (D) UV-vis spectroscopic monitoring of $\mathrm{Tz} 9$ in PBS containing $5 \mathrm{mM}$ glutathione in the presence of SiR shows that tetrazine absorption slowly decreases in the dark, rapidly recovers upon illumination, and again decreases in the dark. (E) The efficiency of tetrazine ligation with MeTzHalo in live cells is improved 3.6-fold through photocatalysis and is more comparable to that observed when HeLa cells expressing HaloTag-H2BGFP were directly tagged with TAMRA-Halo (Fig 5E, right). 
extracellular environment. While a range of enzymes and reductants including glutathione can mitigate intracellular oxidative stress, ${ }^{89}$ the extracellular environment lacks comparable mechanisms for resolving oxidative damage due to ${ }^{1} \mathrm{O}_{2}$. We found that cellular SiR-photocatalysis was successful when carried out in the presence of $2 \mathrm{mM}$ sodium ascorbate- a non-toxic reductant with low membrane permeability. ${ }^{90}$ When irradiated by $660 \mathrm{~nm}$ light, SiR-tJF 646 is deactivated by ascorbate and is therefore incapable of sensitizing extracellular ${ }^{1} \mathrm{O}_{2}$. However, due to the impermeability of ascorbate, intracellular SiR-tJF 646 remains active and capable of catalyzing $\mathrm{DHTz}$ oxidation. As shown in Fig 4E, HeLa cells expressing HaloTag-MitoGFP (mitochondria) were tagged with DHTz-Halo $(10 \mu \mathrm{M})$, washed and then treated with o-TCO-TAMRA $(2.5 \mu \mathrm{M})$, sodium ascorbate $(2.0 \mathrm{mM})$ and $\mathbf{S i R}(2.5 \mu \mathrm{M})$ for $20 \mathrm{~min}$. In time course experiments, cells were then irradiated at $660 \mathrm{~nm}$ and $450 \mathrm{~mW} / \mathrm{cm}^{2}$ using an LED light source. All labeling experiments were carried out for a total of $30 \mathrm{~min}$ : after irradiation for the desired amount of time (0-30 $\mathrm{min})$, the cells were kept in the dark for the balance of the 10 min, at which point the TCO reagent was chased by a non-fluorescent tetrazine, and the cells were lysed and analyzed by SDS-PAGE. (Fig 4E). Paralleling the observations in Figure 3, CABL is less rapid with $\mathrm{SiR} /$ far red catalysis, with maximum labeling achieved after 30 minutes of illumination. CABL using SiR/ $660 \mathrm{~nm}$ light could also be used to activate labeling in the nucleus, actin or cytosol (Fig S20).

Overall, CABL was successful in the majority of subcellular environments that were tested, but we did observe background oxidation/Diels-Alder reaction in the absence of light in experiments with a DHTz derivative of ceramide, and also in an attempt to activate a DHTz-Halotag conjugate in HeLa cells expressing Halo-mCherryPDGFR on the extracellular surface.

\section{CABL improves the efficiency of 'regular' tetrazine ligations}

As discussed above, the efficiency of CABL in live HeLa cells with DHTz-tagged HaloTag-H2B-GFP is comparable to direct labeling by TAMRA-Halo (Fig 5C). By contrast, tagging HaloTag-H2BGFP with a conventional tetrazine, MeTzHalo, followed by labeling with o-TCO-TAMRA is considerably less efficient (Fig 5A, 5E.). We reasoned that the low labeling efficiency may be partly a consequence of tetrazine reduction in the cellular environment, ${ }^{91}$ as illustrated in Fig 5B. Tetrazines are reduced to DHTzs by thiols. ${ }^{91}$ In the presence of $\mathbf{S i R}(4 \mu \mathrm{M})$ but in the dark, incubating $25 \mu \mathrm{M}$ tetrazine 9 with GSH ( $5 \mathrm{mM}$ ) leads to a reduction in absorption at $262 \mathrm{~nm}$, with $\sim 12 \%$ of tetrazine 9 consumed after $110 \mathrm{~min}$ (Fig 5D). Irradiation at $660 \mathrm{~nm}$ light led to rapid and nearly complete recovery of the absorbance at $262 \mathrm{~nm}$. When the light was turned off, reduction of tetrazine 9 resumed. The observation is consistent with a partial reduction of tetrazine 9 to $\mathrm{DHTz} 13$ by GSH, with the recovery of the tetrazine oxidation state upon catalytic photooxidation.

The efficiency of tetrazine ligation with MeTzHalo in live cells was also improved through photocatalysis. As shown in left of Fig $5 \mathrm{E}$, relatively weak fluorescence was observed in HeLa cells expressing HaloTag-H2B-GFP that were sequentially tagged with MeTzHalo, incubated for $2 \mathrm{~h}$, and then labeled with o-TCOTAMRA. However, when $\operatorname{SiR}(2.5 \mu \mathrm{M})$ and $660 \mathrm{~nm}$ light was applied during the conjugation of O-TCO-TAMRA, a 3.6-fold increase in fluorescence was observed (Fig 5E, center). The efficiency of photocatalytic conjugation is more comparable to that observed when HeLa cells expressing HaloTag-H2B-GFP were directly tagged with TAMRA-Halo (Fig 5E, right).
Fluorescence imaging of subcellular targets in live cells labeled by CABL

The ability to photocatalyze the activation of tetrazine ligation was next applied to selective fluorescent labeling and imaging of subcellular targets. Following the same workflow outlined in Fig 4, HeLa cells were transfected with a GFP-HaloTag construct fused to a POI that controls subcellular localization, and then labeled by the small molecule DHTz-Halo. The cells are treated with SiR photocatalyst $(2.5 \mu \mathrm{M})$ and o-TCO-TAMRA $(1.0 \mu \mathrm{M})$, irradiated with $660 \mathrm{~nm}$ light for $20 \mathrm{~min}$, and then fixed (4\% paraformaldehyde), washed, and imaged by confocal microscopy (Fig 6A).

Because DHTz-Halo is tagged to a GFP-fusion protein, a successful experiment is expected to result in colocalization of green (GFP) and red (TAMRA) fluorescence at the subcellular target in transfected cells. As shown in Fig 6B, fluorescent colocalization was observed in $\mathrm{CABL}$ experiments with various subcellular targets including LifeAct (actin), GAP43 (cytoplasm), ActA (mitochondria) and $\mathrm{H} 2 \mathrm{~B}$ (nucleus). TAMRA conjugation was not observed in control experiments where light was omitted, neither by confocal microscopy nor by gel electrophoresis (see irradiation $\mathrm{t}=0$ in Fig $4 \mathrm{E}$ and Fig S19-S20). As expected for transient transfection protocol, only a subset of cells express the fluorescent fusion protein. Fluorophore colocalization was only observed in those cells that expressed the HaloTag-GFP protein complex, and not in neighboring cells that did not display GFP fluorescence (Fig S21 A.)

\section{Live Cell, no-wash Sub-organelle Photopatterning}

Two-photon excitation can provide focused light to biological samples with spatiotemporal control. Fig 7A schematically illustrates how CABL was used in combination with two-photon excitation and confocal microscopy in order to pattern well-defined 3D structures at the subcellular level. Using CABL, two photon excitation microscopy $(880 \mathrm{~nm})$ is used to excite fluorescein and photocatalyze the generation of reactive tetrazines in the subcellular environment, and fluorescent reporters are concentrated in the region of illumination through Diels-Alder chemistry. The rapid kinetics of the tetrazine-TCO conjugation enables stoichiometric labeling ${ }^{92,93}$ at very low concentrations $(<1 \mu \mathrm{M})$ of the fluorescent reporter which is covalently attached in the illuminated area of the live cells under no-wash conditions.

As depicted in Figure 7A, HeLa cells were transfected with HaloTag-H2B-RFP, where RFP is the red fluorescent protein mCherry. The nuclei of the transfected cells were then tagged with DHTzHalo $(10 \mu \mathrm{M})$, washed and then treated with a-TCO-SiR (100 nM) and FDA $(10 \mu \mathrm{M})$. For this experiment, the SiR serves as fluorescent reporter and a two-photon laser provided focused light at the optimal wavelength $(880 \mathrm{~nm})$ for 2-photon excitation of the fluorescein photocatalyst. Because of the high intensity of the light, only brief illumination was required to promote efficient photoactivation and fluorescent labeling. As shown in Figure 7B, illuminating a square region within the cell nucleus resulted in effective labeling after irradiating for 3.3 seconds. As shown in Fig 7E and Fig S22 the intensity of fluorescence at $633 \mathrm{~nm}$ due to the SiR fluorophore was monitored 
A

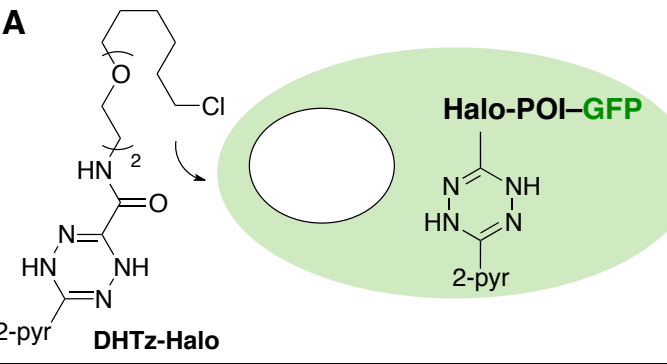

$h v$

$\operatorname{SiR}(2.5 \mu \mathrm{M})$

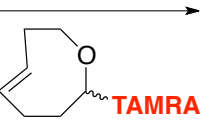

O-TCO-TAMRA

$(1.0 \mu \mathrm{M}) \quad$ selective reaction $=$ green and red colocalization

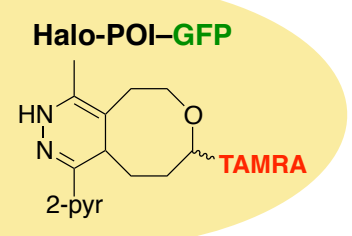

B
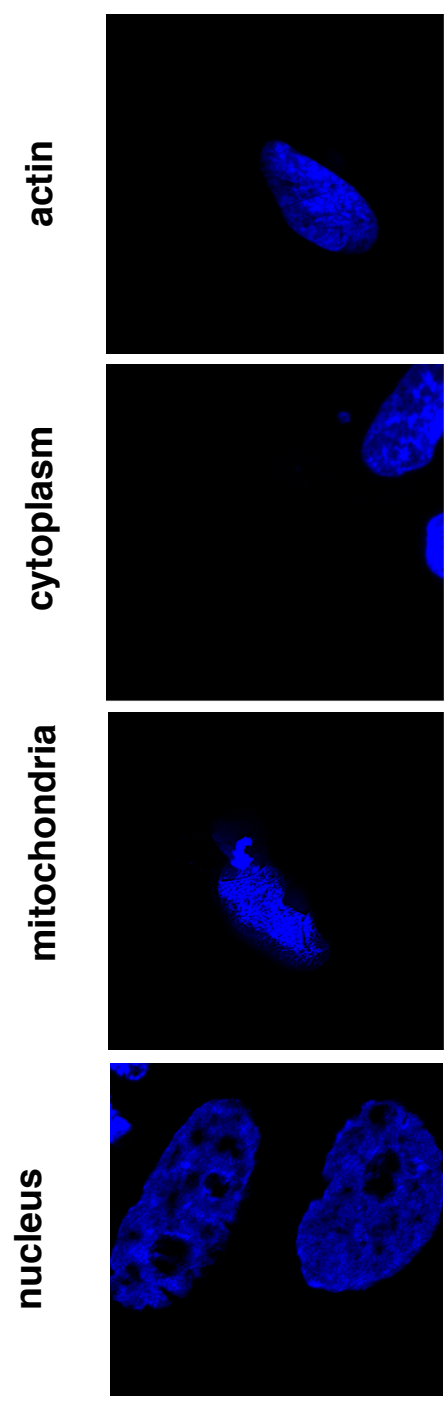

GFP
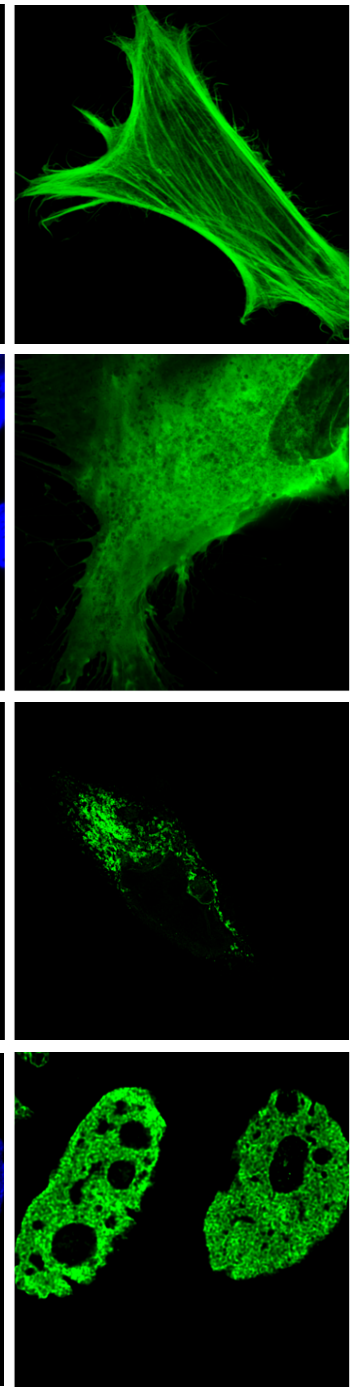

TAMRA
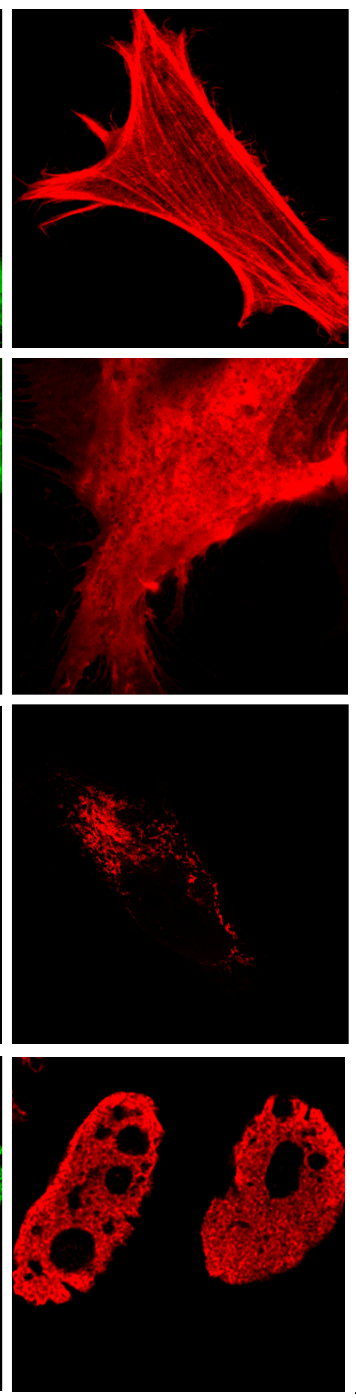

Merge
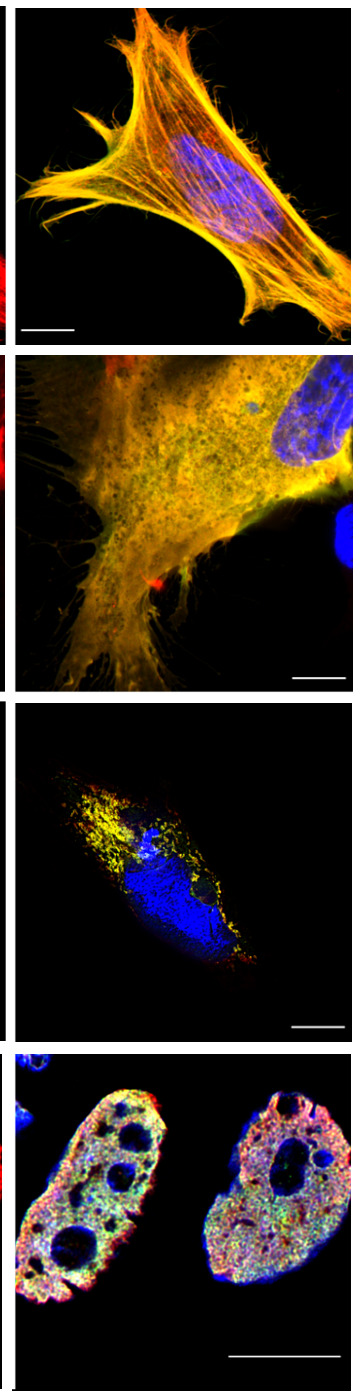

Fig 6. Fluorescence imaging of subcellular targets in live cells labeled by CABL. (A) DHTz-HaloTag is introduced to HeLa cells were transfected with a HaloTag-POI-GFP fusion where the protein of interest (POI) controls subcellular localization. Successful photoactivation and Diels-Alder reaction with TAMRA-TCO results in the colocalization of green fluorescence from the target and red fluorescence from TAMRA. Cells were labeled while live and fixed prior to imaging, and DAPI was added to stain cell nuclei. (B) Confocal fluorescence microscopy images of photoactivate cells with DHTz targeted to LifeAct (actin), GAP43 (cytoplasm), ActA (mitochondria) and $\mathrm{H} 2 \mathrm{~B}$ (nucleus). Scale bar $=10 \mu \mathrm{m}$

in the illuminated region of the nucleus as well as in a non-illuminated square region of equivalent area found directly below. To demonstrate that CABL is light-dose dependent, a separate experiment was carried out where the entire nucleus of a HaloTag-H2BRFP transfected cell was periodically pulsed with light from the 2photon source at $10 \%$ laser power. A movie (supplementary movie
1) and Fig7F show that fluorescence intensity rapidly increases $\left(t_{1 / 2} \sim 7 \mathrm{sec}\right)$ and then stabilizes after each of three light pulses at which point the maximum fluorescence intensity for the region is reached. The apparent bimolecular rate constant $k_{2}(\mathrm{app}) 1 \times 10^{6} \mathrm{M}^{-}$ ${ }^{1} \mathrm{~s}^{-1}$ measured for this reaction in a live cell nucleus is similar to the 

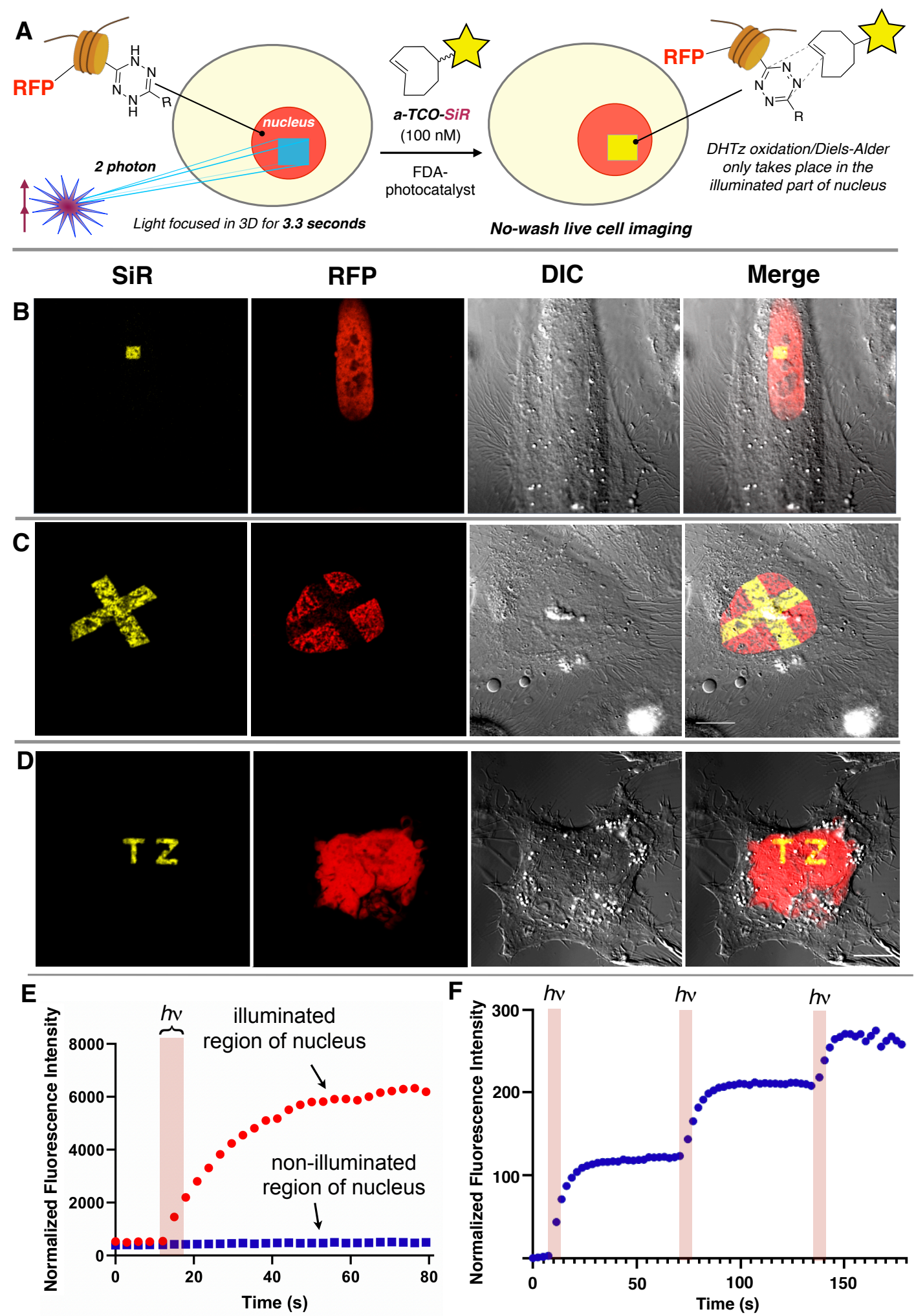

Fig 7. Live cell, no-wash photopatterning on the cell nucleus. (A) In the presence of a-TCO-SiR, two-photon excitation microscopy $(880 \mathrm{~nm})$ is used to activate fluorescein and photocatalyze the generation of reactive tetrazines in nuclei of HaloTag-H2B-RFP transfected cells. The whole nucleus is red-fluorescent, but only the photopatterned regions are labeled by the far-red SiR-dye. Cells are imaged live immediately after 2-photon excitation. (B-D) Illuminating for 3.3 seconds with focused, 2-photon light is used to label (B) square, $(C)$ an ' $X$ ' and (D) letters in the cell nucleus. A high laser power (details) was used in (C) to demonstrate that labeling is effective even under conditions that photobleach the RFP fluorophore. (E) For the experiment in Fig 7B, the intensity of fluorescence at $633 \mathrm{~nm}$ due to the $\mathrm{SiR}$ fluorophore was monitored in the illuminated region of the nucleus as well as in a non-illuminated square region of equivalent area found directly below. (F). Fluorescence intensity timecourse for a cell nucleus of a single cell that was periodically pulsed with light from the 2-photon source at low laser power. Scale bar $=10 \mu \mathrm{m}$ 
in vitro rates observed for a-TCO with $\mathrm{Tz} 2 \mathbf{a}\left(k_{2} 1.46 \times 10^{6} \mathrm{M}^{-1} \mathrm{~s}^{-1}\right.$, Fig $2 c$ ). Interestingly, the rate is $\sim 40 \%$ slower for the experiment in Figs $7 \mathrm{~B}, 7 \mathrm{E}$, and supplementary movie 2 where only the interior of the cell nucleus was activated $k_{2}$ (app) $6 \times 10^{5} \mathrm{M}^{-1} \mathrm{~s}^{-1}$, and may reflect a limitation of diffusion within the nuclear environment. As shown in Fig 7C and 7D, 2-photon irradiation could be used to introduce additional patterns in the live cell nucleus. For the "X" (Fig 7C, Supplementary movie 3), a higher laser power was intentionally used to photobleach the RFP fluorophore, and to show that SiR-fluorescence and RFP photobleaching are colocalized in the experiment. As shown in Fig 7D, CABL can also be used to create letters in the cell nucleus. Supplementary movie 4 of a rotating $3 \mathrm{D}$ projection generated from the $\mathrm{z}$-stack of the cell demonstrates that the photopatterning exhibits a high degree of both lateral and axial resolution.

\section{Spatiotemporally resolved labeling of endogenous MAGL}

CABL was also used for the spatiotemporally resolved labeling of an endogenous protein target in live cells. We constructed a DHTz probe for the covalent modification of monoacylglycerol lipase (MAGL), a serine hydrolase from the endocannabinoid signaling pathway with broad therapeutic potential (Scheme 8A).${ }^{94} \mathrm{DHTz}$ probe 14 was prepared by conjugating 6 (Scheme 2) to a 1-oxa-8azaspiro[4.5] decane scaffold ${ }^{95}$ with an electrophilic hexafluoroisopropyl (HFIP) carbamate group for covalently labeling the active site serine ${ }^{96}$ (Fig 8A).Probe 14 inhibited MAGL activity with $13 \mathrm{nM}$ $\mathrm{IC}_{50}$ in an in vitro assay (Fig S24)..$^{7}$ To test the labeling of endogenous
A
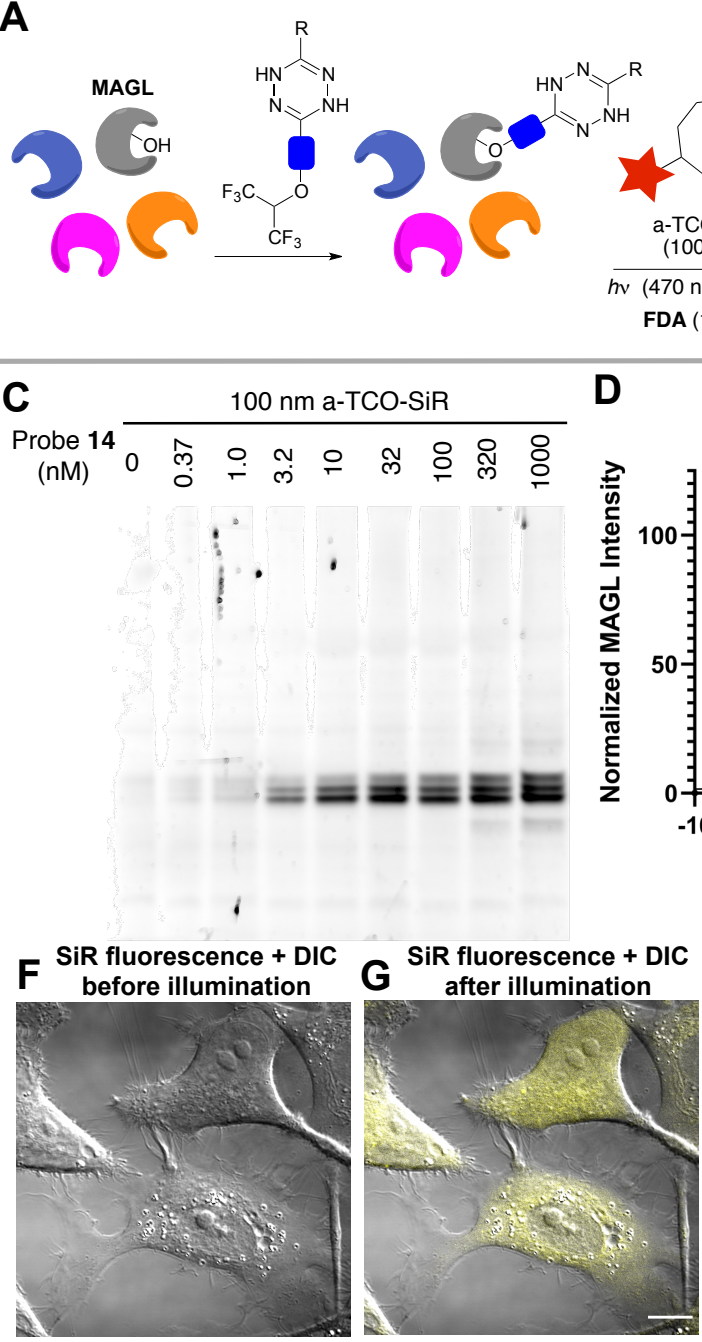

\section{D}
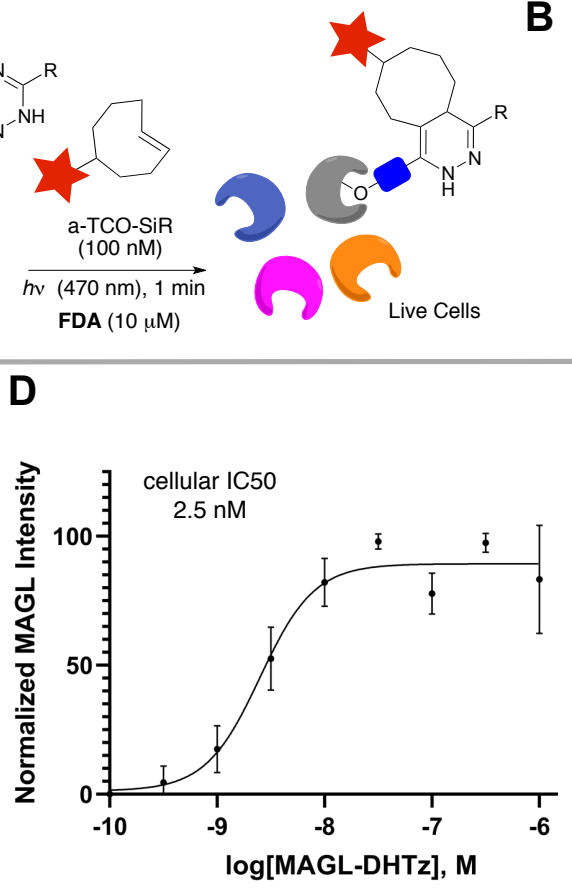

B
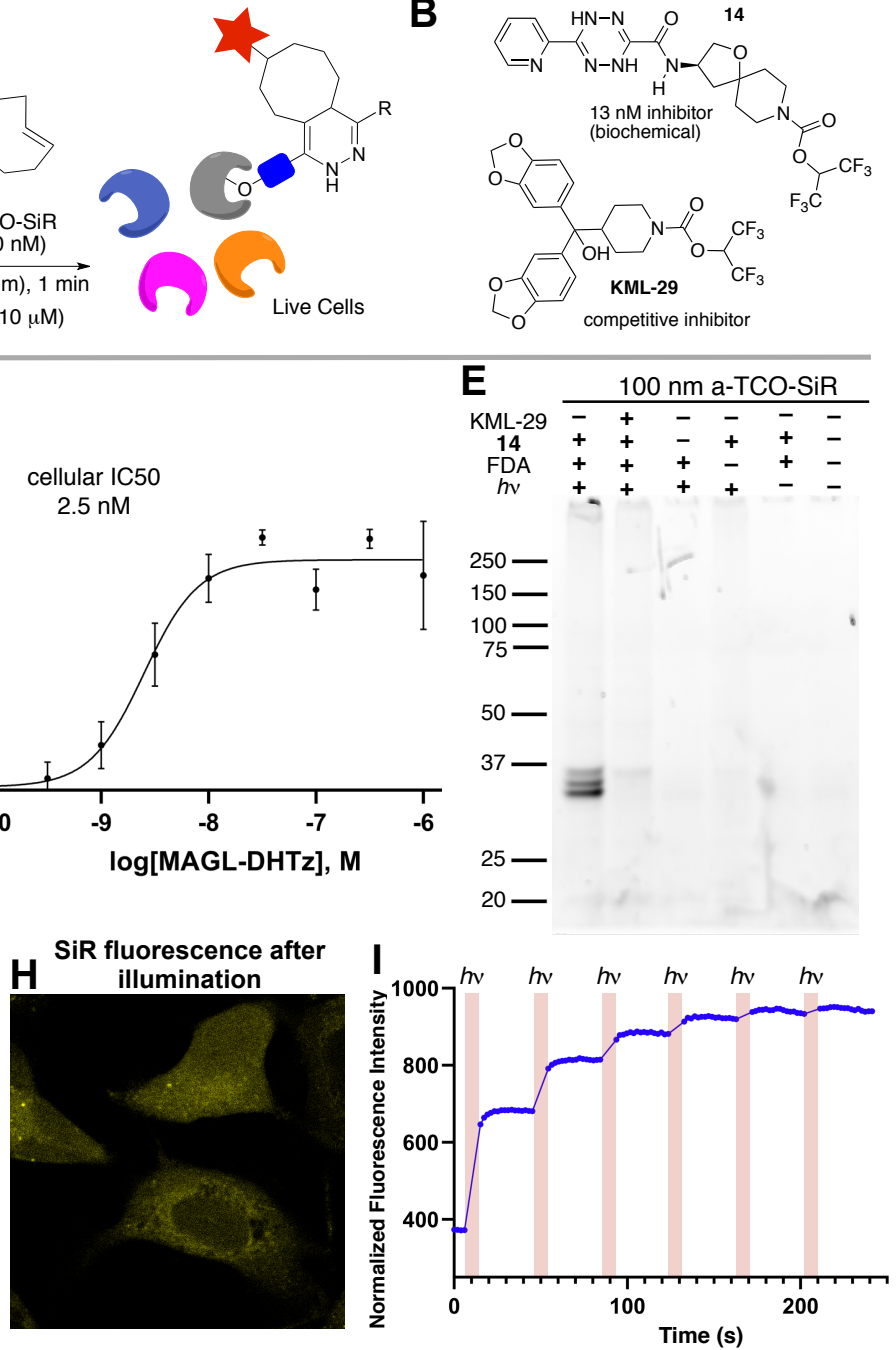

Fig 8. (A) Activity-based labeling of endogenous MAGL in live cells followed by photocatalytic oxidation (B) Structure of MAGL reactive probe $\mathbf{1 4}$ and competitive inhibitor KML-29. (C) Live cells were treated with probe $\mathbf{1 4}$ for $1 \mathrm{~h}$, washed and then treated with FDA $(10 \mu \mathrm{M})$ for $30 \mathrm{~min}$, followed by $2 \mu \mathrm{M}$ a-TCO-SiR for $30 \mathrm{~min}$, and irradiation for 1 min with $470 \mathrm{~nm}$ light. A non-fluorescent tetrazine was added to quench unreacted a-TCO-SiR, and cells were lysed and analyzed by in-gel fluorescence. (C) In-gel fluorescence signals for a dose response of probe 14. (D) Dose response fitting of the fluorescence signals of MAGL normalized by the total protein amount indicated by Coomassie staining. Data are reported as mean \pm SEM $(\mathrm{n}=2)$. (E) Probe $14(3.2 \mathrm{nM}, 1 \mathrm{~h})$ was competed by pretreatment with MAGL inhibitor KML29 $(300 \mathrm{nM}, 1 \mathrm{~h})$. Additional controls include the exclusion of FDA photocatalyst, light or both light and photocatalyst. See Fig S25 for Coomassie staining. (F-I) Confocal microscopy data for live PC3 cells that were labeled by 14 and incubated with a-TCO-SiR before and after wide field illumination with $470 \mathrm{~nm}$ light. (F) SiR fluorescence + DIC prior to illumination. (G) SiR fluorescence + DIC after illumination. (H) SiR fluorescence after illumination. (I) Fluorescence intensity timecourse monitoring of a region of a cell that was periodically pulsed with $488 \mathrm{~nm}$ light (Scale bar=10 $\mu \mathrm{m}$ ). 

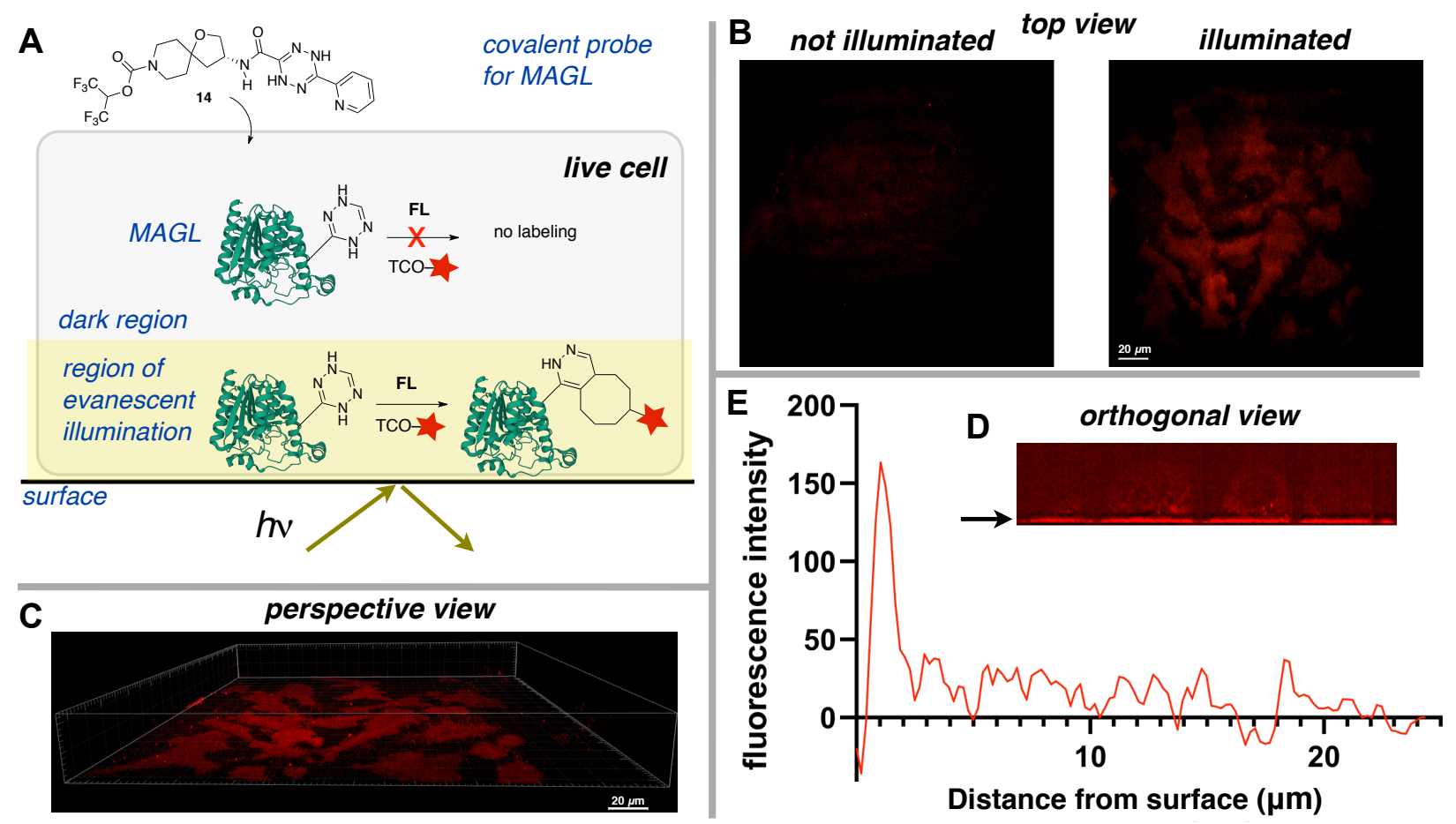

Fig 9. (A) Total infernal reflection fluorescence (TIRF) microscopy was used to activate spatially resolved live-cell labeling of endogenous MAGL proteins that were covalently labeled by probe 14. Only protein-DHTz conjugates in the thin region of evanescent illumination become activated and labeled by the a-TCO-SiR fluorophore. (B) Top view of illuminated and non-illuminated cells visualized by fluorescence microscopy. (C,D) Perspective and orthogonal view of illuminated cells visualized by microscopy. In the orthogonal view, the arrow points to the thin layer that becomes fluorescently labeled near the glass surface. (E) Plot of fluorescent intensity vs distance from surface for the orthogonal projection.

MAGL in live cells, human prostate cancer PC3 cells were treated with probe 14 in Opti-Mem buffer for $1 \mathrm{~h}$, washed and then treated with FDA $(10 \mu \mathrm{M})$ for $30 \mathrm{~min}$. The cells were again washed and then incubated with $100 \mathrm{nM}$ of a-TCO-SiR in Opti-Mem for $5 \mathrm{~min}$ in live cells (Fig 8B), and then irradiated with a $470 \mathrm{~nm}$ LED for $1 \mathrm{~min} .3$ ( $p$-(aminomethyl)phenyl-6-methyltetrazine $9(125 \mu \mathrm{M})$ was then added to quench any unreacted a-TCO-SiR. Cells were lysed and ingel fluorescence was used to assess MAGL-labeling (Fig 8C,D). ${ }^{98}$ Fluorescence was observed for two isoforms of MAGL with minimal non-specific labeling from a-TCO-SiR. Less prominent labeling of an additional protein at $\sim 35 \mathrm{kDa}$ was also observed, which is consistent with the reactivity of HFIP-carbamate probes toward toward $\alpha / \beta$-hydrolase domain 6 (ABHD6) targets. ${ }^{96,98}$ The labeling by probe 14 was dose responsive with a cellular $\mathrm{IC}_{50}$ of $2.5 \mathrm{nM}$, and was competed by a MAGL inhibitor, KML29. ${ }^{96}$ Consistent with the need for photoactivation, labeling was not observed in controls (1) with FDA catalyst but without irradiation, (2) with irradiation but without FDA, or (3) with neither FDA nor irradiation (Fig 8E).

In order to determine the kinetics of the activation of probe 14 on endogenous targets, we labeled PC3 cells, we labeled MAGL using the previously described strategy, treating them with FDA $(10 \mu \mathrm{M})$, washing, and incubating with $50 \mathrm{~nm}$ a-TCO-SiR. Without washing, e fluorescence intensity was monitored via confocal microscopy while periodically irradiating short pulses of light using the $488 \mathrm{~nm}$ laser line (Figs 8F-I). We once again found that SiR signal only increased during photoactivation, and that the fluorescence intensity reached saturation after six pulses of light.
Total infernal reflection fluorescence (TIRF) ${ }^{99}$ microscopy was used to study the ability of CABL to activate spatially resolved livecell labeling of endogenous MAGL (Fig 9A). In TIRF, incident light is internally reflected in a glass substrate, resulting in the generation of an evanescent wave at the glass-liquid interface. As the intensity of the evanescent wave drops exponentially with distance, only chromophores near the coverslip can become efficiently excited. ${ }^{99}$ As MAGL is a membrane associated protein, we reasoned that TIRF would provide method to study the photocatalytic activation and labeling of DHTz-tagged MAGL at the liquid-glass surface. As DHTztagged protein beyond the region evanescent illumination would not be oxidized, labeling is only expected in the thin region near the glass surface (Fig 9A). PC3 cells were plated on piranha-cleaned, poly-Lysine-coated glass, and sequentially treated with probe 14 in OptiMem buffer for $1 \mathrm{~h}$, washed and then treated with FDA $(10 \mu \mathrm{M})$ for $30 \mathrm{~min}$. The cells were washed and then incubated with $100 \mathrm{nM}$ of a-TCO-SiR in Opti-Mem for 5 min in live cells (Fig 7B), and then promptly illuminated with a $488 \mathrm{~nm}$ laser at the critical angle for TIRF irradiation. a-TCO-SiR fluorescence in the cells first was detected with TIRF using the $637 \mathrm{~nm}$ laser. Fig 9B displays two adjacent $200 \mu \mathrm{m}^{2}$ areas of cells, of which only one was irradiated. a-TCO$\mathrm{SiR}$ fluorescence was higher in the cells irradiated (Fig 9B). To examine the depth of labeling, a z-stack of images through the sample was acquired with spinning disk confocal microscopy (Fig 9C-E). In the $3 \mathrm{D}$ projection image of an illuminated area in Fig 9C, it is evident that cells were prominently labeled only near the glass interface. An axial view orthogonal stack in Fig 9D was plotted in Fig 9E, and shows that fluorescent intensity was highest within $1 \mu \mathrm{m}$ from the 
glass surface and dropped off rapidly thereafter. Together, the results illustrate spatiotemporally controlled activation of the DHTzlabeled MAGL protein in response to photocatalysis.

\section{Conclusions}

Catalytic Activation of Bioorthogonal Chemistry with Light (CABL) is a spatiotemporally controlled method for the labeling and patterning of biomolecules in live cells. Unreactive dihydrotetrazines are photocatalytically oxidized inside live cells to produce reactive tetrazines that are immediately captured by a trans-cyclooctene (TCO) dienophile with kinetics exceeding $k_{2} 10^{6} \mathrm{M}^{-1} \mathrm{~s}^{-1}$. Fluorescein or silarhodamine dyes are used with activation at 470 or $660 \mathrm{~nm}$, and strategies for limiting the extracellular production of singlet oxygen were developed to increase the cytocompatibility. Fusions of the HaloTag self-labeling protein were used to localize DHTz-tags and demonstrate high-yielding subcellular activation and labeling of proteins in the nucleus, mitochondria, actin or cytoplasm. 2-Photon excitation microscopy was used to demonstrate that $\mathrm{CABL}$ is light-dose dependent and to selectively pattern live cells at the sub-organelle level under no-wash conditions. Spatially resolved live-cell labeling of an endogenous protein target was accomplished by using TIRF microscopy to selectively activate intracellular monoacylglycerol lipase tagged with DHTz-labeled small molecule covalent inhibitor. Beyond spatiotemporally controlled labeling, photocatalysis also improves the efficiency of an 'ordinary' tetrazine ligations by rescuing the reactivity of commonly used 3aryl-6-methyltetrazine reporters that become partially reduced to DHTzs inside cells. We anticipate that the spatiotemporal control and fast rates of photoactivation and labeling of CABL will enable a range of biomolecular labeling applications in living systems.

\section{SUPPORTING INFORMATION}

Synthetic procedures and compound characterization data; methods for determining dihydrotetrazine stability and photooxidation kinetics; Diels-Alder kinetics; description of plasmids; protocols for HaloTag conjugation and photoactivation; protocols for photoactivation of DHTz-HaloTag in e. coli; protocols for photoactivation of DHTz-HaloTag in HeLa Cells; protocols for photoactivation of DHTz-MAGL in PC3 Cells.

The Supporting Information is available free of charge on the ACS Publications website. The file type is PDF.

\section{AUTHOR INFORMATION}

\section{Corresponding Authors}

*jmfox@udel.edu

The authors declare the following competing financial interest(s): C.W.A. is an employee of Pfizer Inc.

\section{ACKNOWLEDGMENT}

We thank Luke Lavis and Jonathan Grimm of HHMI for a gift of SiR-tJF $\mathbf{6 4 6}_{\mathbf{6}}$. We thank Lucy Stevens (Pfizer) for determining biochemical MAGL potency. We thank Colin Thorpe (UD), Sam Scinto (UD) and Julia Rosenberger (UD) for insightful discussions. This work was supported by NIH (R01GM132460) and Pfizer. Instrumentation was supported by NIH awards P20GM104316, P20GM103446, S10OD025185, S10OD026951, S10OD016267, S10 OD016361, and S10 OD30321. Facilities and instrumentation were also supported by NSF through the University of Delaware Materials Research Science and Engineering Center, DMR-2011824. 
SYNOPSIS TOC (Word Style "SN_Synopsis_TOC").
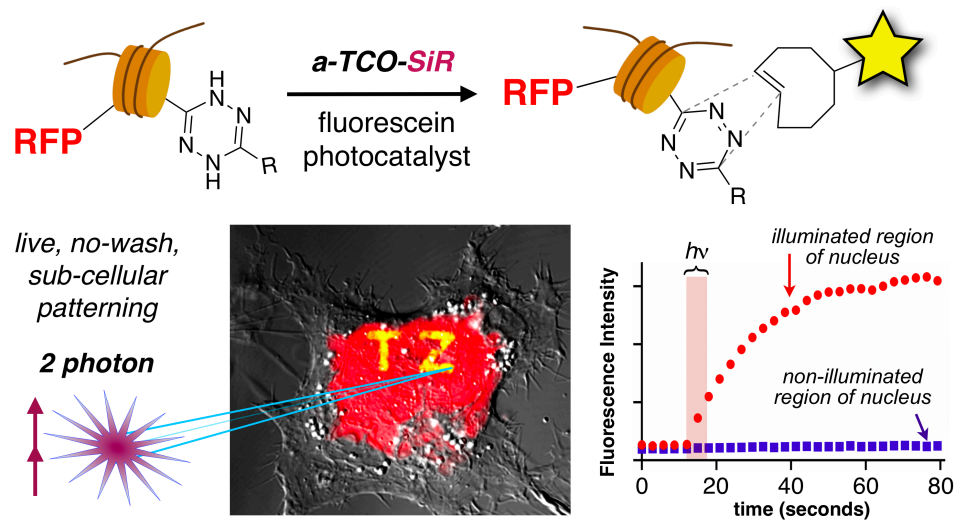


\section{REFERENCES}

(1) Klán, P.; Šolomek, T.; Bochet, C. G.; Blanc, A.; Givens, R.; Rubina, M.; Popik, V.; Kostikov, A.; Wirz, J. Photoremovable Protecting Groups in Chemistry and Biology: Reaction Mechanisms and Efficacy. Chem. Rev. 2013, 113, 119-191.

(2) Kumar, G. S.; Lin, Q. Light-Triggered Click Chemistry. Chem. Rev. 2021, 121, 6991-

7031.

(3) Hüll, K.; Morstein, J.; Trauner, D. In Vivo Photopharmacology. Chem. Rev. 2018, 118, 10710-10747.

(4) Lippincott-Schwartz, J.; Snapp, E.; Kenworthy, A. Studying protein dynamics in living cells. Nat. Rev. Mol. Cell Biol. 2001, 2, 444-456.

(5) Lorén, N.; Hagman, J.; Jonasson, J. K.; Deschout, H.; Bernin, D.; Cella-Zanacchi, F.; Diaspro, A.; McNally, J. G.; Ameloot, M.; Smisdom, N.; Nydén, M.; Hermansson, A.-M.; Rudemo, M.; Braeckmans, K. Fluorescence recovery after photobleaching in material and life sciences: putting theory into practice. Q. Rev. Biophys. 2015, 48, 323-387.

(6) Lippincott-Schwartz, J.; Patterson, G. H. Photoactivatable fluorescent proteins for diffraction-limited and super-resolution imaging. Trends Cell Biol. 2009, 19, 555-565.

(7) Wachter, R. M. Photoconvertible Fluorescent Proteins and the Role of Dynamics in Protein Evolution. Int. J. Mol. Sci. 2017, 18, 1792.

(8) Zhou, X. X.; Lin, M.Z. Photoswitchable fluorescent proteins: ten years of colorful chemistry and exciting applications. Curr. Opin. Chem. Biol. 2013, 17, 682-690.

(9) Banala, S.; Maurel, D.; Manley, S.; Johnsson, K. A caged, localizable rhodamine derivative for superresolution microscopy. ACS Chem. Biol. 2012, 7, 289-293.

(10) Belov, V. N.; Wurm, C. A.; Boyarskiy, V. P.; Jakobs, S.; Hell, S. W. Rhodamines NN: a novel class of caged fluorescent dyes. Angew. Chem. Int. Ed. Engl. 2010, 49, 3520-3523.

(11) Grimm, J. B.; Klein, T.; Kopek, B. G.; Shtengel, G.; Hess, H. F.; Sauer, M.; Lavis, L. D. Synthesis of a Far-Red Photoactivatable Silicon-Containing Rhodamine for Super-Resolution Microscopy. Angew. Chem. Int. Ed. Engl. 2016, 55, 1723-1727.

(12) Kashima, H.; Kamiya, M.; Obata, F.; Kojima, R.; Nakano, S.; Miura, M.; Urano, Y. Photoactivatable fluorophores for durable labelling of individual cells. Chem. Commun. 2021, 57, 58025805.

(13) Puliti, D.; Warther, D.; Orange, C.; Specht, A.; Goeldner, M. Small photoactivatable molecules for controlled fluorescence activation in living cells. Bioorg. Med. Chem. 2011, 19, 10231029.

(14) Wysocki, L. M.; Grimm, J. B.; Tkachuk, A. N.; Brown, T. A.; Betzig, E.; Lavis, L. D. Facile and general synthesis of photoactivatable xanthene dyes. Angew. Chem. Int. Ed. Engl. 2011, 50, 11206-11209.

(15) Grimm, J. B.; English, B. P.; Choi, H.; Muthusamy, A. K.; Mehl, B. P.; Dong, P.; Brown, T. A.; Lippincott-Schwartz, J.; Liu, Z.; Lionnet, T.; Lavis, L. D. Bright photoactivatable fluorophores for single-molecule imaging. Nat. Meth. 2016, 13, 985-988.

(16) Frei, M. S.; Hoess, P.; Lampe, M.; Nijmeijer, B.; Kueblbeck, M.; Ellenberg, J.; Wadepohl, H.; Ries, J.; Pitsch, S.; Reymond, L.; Johnsson, K. Photoactivation of silicon rhodamines via a light-induced protonation. Nat. Commun. 2019, 10, 4580.

(17) Patterson, G.; Davidson, M.; Manley, S.; Lippincott-Schwartz, J. Superresolution imaging using single-molecule localization. Annu. Rev. Phys. Chem. 2010, 61, 345-367.

(18) Scinto, S. L.; Bilodeau, D. A.; Hincapie, R.; Lee, W.; Nguyen, S. S.; Xu, M.; am Ende, C. W.; Finn, M. G.; Lang, K.; Lin, Q.; Pezacki, J. P.; Prescher, J. A.; Robillard, M. S.; Fox, J. M. Bioorthogonal chemistry. Nat. Rev. Methods Primers 2021, 1, 30. 
(19) Sletten, E. M.; Bertozzi, C. R. Bioorthogonal Chemistry: Fishing for Selectivity in a Sea of Functionality. Angew. Chem. Int. Ed. Engl. 2009, 48, 6974-6998.

(20) Lopez Aguilar, A.; Briard, J. G.; Yang, L.; Ovryn, B.; Macauley, M. S.; Wu, P. Tools for Studying Glycans: Recent Advances in Chemoenzymatic Glycan Labeling. ACS Chem. Biol. 2017, 12, 611-621.

(21) Liang, D.; Wu, K.; Tei, R.; Bumpus, T. W.; Ye, J.; Baskin, J. M. A real-time, click chemistry imaging approach reveals stimulus-specific subcellular locations of phospholipase D activity. Proc. Nat. Acad. Sci. 2019, 116, 15453-15462.

(22) Ganz, D.; Harijan, D.; Wagenknecht, H.-A. Labelling of DNA and RNA in the cellular environment by means of bioorthogonal cycloaddition chemistry. RSC Chem. Biol. 2020, 1, 86-97.

(23) Lang, K.; Chin, J. W. Bioorthogonal Reactions for Labeling Proteins. ACS Chem. Biol. 2014, 9, 16-20.

(24) Zhang, Y.; Park, K.-Y.; Suazo, K. F.; Distefano, M. D. Recent progress in enzymatic protein labelling techniques and their applications. Chem. Soc. Rev. 2018, 47, 9106-9136.

(25) Murrey, H. E.; Judkins, J. C.; am Ende, C. W.; Ballard, T. E.; Fang, Y.; Riccardi, K.; Di, L.; Guilmette, E. R.; Schwartz, J. W.; Fox, J. M.; Johnson, D. S. Systematic Evaluation of Bioorthogonal Reactions in Live Cells with Clickable HaloTag Ligands: Implications for Intracellular Imaging. J. Am. Chem. Soc. 2015, 137, 11461-11475.

(26) Lang, K.; Chin, J. W. Cellular incorporation of unnatural amino acids and bioorthogonal labeling of proteins. Chem. Rev. 2014, 114, 4764-4806.

(27) Cañeque, T.; Müller, S.; Rodriguez, R. Visualizing biologically active small molecules in cells using click chemistry. Nat. Rev. Chem. 2018, 2, 202-215.

(28) Lambert, W. D.; Fang, Y.; Mahapatra, S.; Huang, Z.; Am Ende, C. W.; Fox, J. M. Installation of Minimal Tetrazines through Silver-Mediated Liebeskind-Srogl Coupling with Arylboronic Acids. J. Am. Chem. Soc. 2019, 141, 17068-17074.

(29) Xie, Y.; Fang, Y.; Huang, Z.; Tallon, A.; am Ende, C. W.; Fox, J. Divergent Synthesis of Monosubstituted and Unsymmetrical 3,6- Disubstituted Tetrazines from Carboxylic Ester Precursors. Angew. Chem. Int. Ed. Engl. 2020, 59.

(30) Cravatt, B. F.; Hsu, K.-L.; Weerapana, E.: Activity-Based Protein Profiling; Springer, 2019; Vol. 420.

(31) Herner, A.; Lin, Q. Photo-Triggered Click Chemistry for Biological Applications. Top. Curr. Chem. 2015, 374, 1 .

(32) Tasdelen, M. A.; Yagci, Y. Light-Induced Click Reactions. Angew. Chem. Int. Ed. 2013, $52,5930-5938$.

(33) Song, W.; Wang, Y.; Qu, J.; Madden, M. M.; Lin, Q. A photoinducible 1,3-dipolar cycloaddition reaction for rapid, selective modification of tetrazole-containing proteins. Angew. Chem. Int. Ed. 2008, 47, 2832-2835.

(34) An, P.; Lewandowski, T. M.; Erbay, T. G.; Liu, P.; Lin, Q. Sterically Shielded, Stabilized Nitrile Imine for Rapid Bioorthogonal Protein Labeling in Live Cells. J. Am. Chem. Soc. 2018, 140, 4860-4868.

(35) Yu, Z.; Lin, Q. Design of Spiro[2.3]hex-1-ene, a Genetically Encodable Double-Strained Alkene for Superfast Photoclick Chemistry. J. Am. Chem. Soc. 2014, 136, 4153-4156.

(36) Shah, L.; Laughlin, S. T.; Carrico, I. S. Light-Activated Staudinger-Bertozzi Ligation within Living Animals. J. Am. Chem. Soc. 2016, 138, 5186-5189.

(37) Shete, A. U.; El-Zaatari, B. M.; French, J. M.; Kloxin, C. J. Blue-light activated rapid polymerization for defect-free bulk $\mathrm{Cu}(\mathrm{i})$-catalyzed azide-alkyne cycloaddition (CuAAC) crosslinked networks. Chem. Commun. 2016, 52, 10574-10577.

(38) Lim, R. K. V.; Lin, Q. Azirine ligation: fast and selective protein conjugation via photoinduced azirine-alkene cycloaddition. Chem. Commun. 2010, 46, 7993-7995.

(39) Gann, A. W.; Amoroso, J. W.; Einck, V. J.; Rice, W. P.; Chambers, J. J.; Schnarr, N. A. A photoinduced, benzyne click reaction. Org. Lett. 2014, 16, 2003-2005. 
(40) Gao, J.; Xiong, Q.; Wu, X.; Deng, J.; Zhang, X.; Zhao, X.; Deng, P.; Yu, Z. Direct ringstrain loading for visible-light accelerated bioorthogonal ligation via diarylsydnonedibenzo[b,f] $[1,4,5]$ thiadiazepine photo-click reactions. Commun. Chem. 2020, 29.

(41) Zhang, L.; Zhang, X.; Yao, Z.; Jiang, S.; Deng, J.; Li, B.; Yu, Z. Discovery of Fluorogenic Diarylsydnone-Alkene Photoligation: Conversion of ortho-Dual-Twisted Diarylsydnones into Planar Pyrazolines. J. Am. Chem. Soc. 2018, 140, 7390-7394.

(42) Li, J.; Kong, H.; Huang, L.; Cheng, B.; Qin, K.; Zheng, M.; Yan, Z.; Zhang, Y. Visible Light-Initiated Bioorthogonal Photoclick Cycloaddition. J Am Chem Soc 2018, 140, 14542-14546.

(43) Li, J.; Kong, H.; Zhu, C.; Zhang, Y. Photo-controllable bioorthogonal chemistry for spatiotemporal control of bio-targets in living systems. Chem. Sci. 2020, 11, 3390-3396.

(44) Bruins, J. J.; Albada, B.; van Delft, F. ortho-Quinones and Analogues Thereof: Highly Reactive Intermediates for Fast and Selective Biofunctionalization. Chem. Eur. J. 2018, 24, 4749-4756.

(45) Bruins, J. J.; Blanco-Ania, D.; Van Der Doef, V.; Van Delft, F. L.; Albada, B. Orthogonal, dual protein labelling by tandem cycloaddition of strained alkenes and alkynes to orthoquinones and azides. Chem. Commun. 2018, 54, 7338-7341.

(46) Arumugam, S.; Popik, V. V. Photochemical Generation and the Reactivity ofoNaphthoquinone Methides in Aqueous Solutions. J. Am. Chem. Soc. 2009, 131, 11892-11899.

(47) Feist, F.; Rodrigues, L. L.; Walden, S. L.; Krappitz, T. W.; Dargaville, T. R.; Weil, T.; Goldmann, A. S.; Blinco, J. P.; Barner-Kowollik, C. Light-induced Ligation of o-Quinodimethanes with Gated Fluorescence Self-reporting. J. Am. Chem. Soc. 2020, 142, 7744-7748.

(48) Bruins, J. J.; Westphal, A. H.; Albada, B.; Wagner, K.; Bartels, L.; Spits, H.; Van Berkel, W. J. H.; Van Delft, F. L. Inducible, Site-Specific Protein Labeling by Tyrosine Oxidation-StrainPromoted (4 + 2) Cycloaddition. Bioconj. Chem. 2017, 28, 1189-1193.

(49) Singh, K.; Fennell, C. J.; Coutsias, E. A.; Latifi, R.; Hartson, S.; Weaver, J. D. Light Harvesting for Rapid and Selective Reactions: Click Chemistry with Strain-Loadable Alkenes. Chem 2018, 4, 124-137.

(50) Darko, A.; Wallace, S.; Dmitrenko, O.; Machovina, M. M.; Mehl, R. A.; Chin, J. W.; Fox, J. M. Conformationally Strained trans-Cyclooctene with Improved Stability and Excellent Reactivity in Tetrazine Ligation. Chem. Sci. 2014, 5, 3770-3776.

(51) Selvaraj, R.; Fox, J. M. trans-Cyclooctene--a stable, voracious dienophile for bioorthogonal labeling. Curr. Opin. Chem. Biol. 2013, 17, 753-760.

(52) Wu, H.; Devaraj, N. K. Inverse Electron-Demand Diels-Alder Bioorthogonal Reactions. Top. Curr. Chem. 2016, 374, 3.

(53) Wu, H.; Devaraj, N. K. Advances in Tetrazine Bioorthogonal Chemistry Driven by the Synthesis of Novel Tetrazines and Dienophiles. Acc Chem Res 2018, 51, 1249-1259.

(54) Devaraj, N. K.; Hilderbrand, S.; Upadhyay, R.; Mazitschek, R.; Weissleder, R. Bioorthogonal Turn-On Probes for Imaging Small Molecules inside Living Cells. Angew. Chem. Int. Ed. Engl. 2010, 49, 2869-2872.

(55) Thompson, A. D.; Bewersdorf, J.; Toomre, D.; Schepartz, A. HIDE Probes: A New Toolkit for Visualizing Organelle Dynamics, Longer and at Super-Resolution. Biochemistry 2017, 56, 5194-5201.

(56) Werther, P.; Yserentant, K.; Braun, F.; Grußmayer, K.; Navikas, V.; Yu, M.; Zhang, Z.; Ziegler, M. J.; Mayer, C.; Gralak, A. J.; Busch, M.; Chi, W.; Rominger, F.; Radenovic, A.; Liu, X.; Lemke, E. A.; Buckup, T.; Herten, D.-P.; Wombacher, R. Bio-orthogonal Red and Far-Red Fluorogenic Probes for Wash-Free Live-Cell and Super-resolution Microscopy. ACS Cent. Sci. 2021.

(57) Beliu, G.; Kurz, A. J.; Kuhlemann, A. C.; Behringer-Pliess, L.; Meub, M.; Wolf, N.; Seibel, J.; Shi, Z.-D.; Schnermann, M.; Grimm, J. B.; Lavis, L. D.; Doose, S.; Sauer, M. Bioorthogonal labeling with tetrazine-dyes for super-resolution microscopy. Commun. Biol. 2019, 2, 261.

(58) Nikić, I.; Estrada Girona, G.; Kang, J. H.; Paci, G.; Mikhaleva, S.; Koehler, C.; Shymanska, N. V.; Ventura Santos, C.; Spitz, D.; Lemke, E. A. Debugging Eukaryotic Genetic Code 
Expansion for Site-Specific Click-PAINT Super-Resolution Microscopy. Angew. Chem. Int. Ed. Engl. 2016, 55, 16172-16176.

(59) Uttamapinant, C.; Howe, J. D.; Lang, K.; Beránek, V.; Davis, L.; Mahesh, M.; Barry, N. P.; Chin, J. W. Genetic Code Expansion Enables Live-Cell and Super-Resolution Imaging of SiteSpecifically Labeled Cellular Proteins. J. Am. Chem. Soc. 2015, 137, 4602-4605.

(60) Kumar, P.; Zainul, O.; Camarda, F. M.; Jiang, T.; Mannone, J. A.; Huang, W.; Laughlin, S. T. Caged Cyclopropenes with Improved Tetrazine Ligation Kinetics. Org. Lett. 2019, 21, 3721-3725.

(61) Jiang, T.; Kumar, P.; Huang, W.; Kao, W. S.; Thompson, A. O.; Camarda, F. M.; Laughlin, S. T. Modular Enzyme- and Light-Based Activation of Cyclopropene-Tetrazine Ligation. ChemBioChem 2019, 20, 2222-2226.

(62) Mayer, S. V.; Murnauer, A.; Wrisberg, M. K.; Jokisch, M. L.; Lang, K. Photo-induced and Rapid Labeling of Tetrazine-Bearing Proteins via Cyclopropenone-Caged Bicyclononynes. Angew. Chem. Int. Ed. 2019, 58, 15876-15882.

(63) Selvaraj, R.; Fox, J. M. An efficient and mild oxidant for the synthesis of s-tetrazines. Tetrahedron Lett. 2014, 55, 4795-4797.

(64) Ehret, F.; Wu, H.; Alexander, S. C.; Devaraj, N. K. Electrochemical Control of Rapid Bioorthogonal Tetrazine Ligations for Selective Functionalization of Microelectrodes. J. Am. Chem. Soc. 2015, 137, 8876-8879.

(65) Min, D. J.; Miomandre, F.; Audebert, P.; Kwon, J. E.; Park, S. Y. s-Tetrazines as a New Electrode-Active Material for Secondary Batteries. ChemSusChem 2019, 12, 503-510.

(66) Nickerl, G.; Senkovska, I.; Kaskel, S. Tetrazine functionalized zirconium MOF as an optical sensor for oxidizing gases. Chem. Commun. 2015, 51, 2280-2282.

(67) Liu, L.; Zhang, D.; Johnson, M.; Devaraj, N. K. Light-activated tetrazines enable livecell spatiotemporal control of bioorthogonal reactions. bioRxiv 2020, 2020.2012.2001.405423.

(68) Albada, B.; Keijzer, J. F.; Zuilhof, H.; van Delft, F. Oxidation-Induced “One-Pot” Click Chemistry. Chem. Rev. 2021, 121, 7032-7058.

(69) Zhang, H.; Trout, W. S.; Liu, S.; Andrade, G. A.; Hudson, D. A.; Scinto, S. L.; Dicker, K. T.; Li, Y.; Lazouski, N.; Rosenthal, J.; Thorpe, C.; Jia, X.; Fox, J. M. Rapid Bioorthogonal Chemistry Turn-on through Enzymatic or Long Wavelength Photocatalytic Activation of Tetrazine Ligation. J. Am. Chem. Soc. 2016, 138, 5978-5983.

(70) Carthew, J.; Frith, J. E.; Forsythe, J. S.; Truong, V. X. Polyethylene glycol-gelatin hydrogels with tuneable stiffness prepared by horseradish peroxidase-activated tetrazine-norbornene ligation. J. Mater. Chem. B. 2018, 6, 1394-1401.

(71) Truong, V. X.; Tsang, K. M.; Ercole, F.; Forsythe, J. S. Red Light Activation of Tetrazine-Norbornene Conjugation for Bioorthogonal Polymer Cross-Linking across Tissue. Chem. Mat. 2017, 29, 3678-3685.

(72) Liu, Z.; Lv, Y.; Zhu, A.; An, Z. One-Enzyme Triple Catalysis: Employing the Promiscuity of Horseradish Peroxidase for Synthesis and Functionalization of Well-Defined Polymers. ACS Macro Lett. 2018, 7, 1-6.

(73) Fu, M.; Xiao, Y.; Qian, X.; Zhao, D.; Xu, Y. A design concept of long-wavelength fluorescent analogs of rhodamine dyes: replacement of oxygen with silicon atom. Chem. Commun. 2008, 1780-1782.

(74) Koide, Y.; Urano, Y.; Hanaoka, K.; Terai, T.; Nagano, T. Evolution of Group 14 Rhodamines as Platforms for Near-Infrared Fluorescence Probes Utilizing Photoinduced Electron Transfer. ACS Chem. Biol. 2011, 6, 600-608.

(75) Koide, Y.; Urano, Y.; Hanaoka, K.; Piao, W.; Kusakabe, M.; Saito, N.; Terai, T.; Okabe, T.; Nagano, T. Development of NIR Fluorescent Dyes Based on Si-rhodamine for in Vivo Imaging. $J$. Am. Chem. Soc. 2012, 134, 5029-5031.

(76) Grimm, J. B.; Brown, T. A.; Tkachuk, A. N.; Lavis, L. D. General Synthetic Method for Si-Fluoresceins and Si-Rhodamines. ACS Cent. Sci. 2017, 3, 975-985. 
(77) Wang, C.; Zhang, H.; Zhang, T.; Zou, X.; Wang, H.; Rosenberger, J. E.; Vannam, R.; Trout, W. S.; Grimm, J. B.; Lavis, L. D.; Thorpe, C.; Jia, X.; Li, Z.; Fox, J. M. Enabling In Vivo Photocatalytic Activation of Rapid Bioorthogonal Chemistry by Repurposing Silicon-Rhodamine Fluorophores as Cytocompatible Far-Red Photocatalysts. J. Am. Chem. Soc. 2021, 143, 10793-10803.

(78) Wang, D.; Chen, W.; Zheng, Y.; Dai, C.; Wang, L.; Wang, B.: A general and efficient entry to asymmetric tetrazines for click chemistry applications. In Heterocycl. Commun., 2013; Vol. 19; pp 171.

(79) Pilgram, K.; Skiles, R. D. Unsymmetrically 3,6-disubstituted s-tetrazines. Synthesis of 3aryl-6-(perfluoroalkyl)-1,2,4,5-tetrazines and 1,2-dihydro derivatives. J. Org. Chem. 1976, 41, 33923395.

(80) Chung, S. W.; Uccello, D. P.; Choi, H. W.; Montgomery, J. I.; Chen, J. S. Trimethylaluminium-Facilitated Direct Amidation of Carboxylic Acids. Synlett 2011, 2072-2074.

(81) To remove adventitous metal impurities, PBS buffer was purified by filtration through chelex resin prior to use.

(82) Karver, M. R.; Weissleder, R.; Hilderbrand, S. A. Synthesis and Evaluation of a Series of 1,2,4,5-Tetrazines for Bioorthogonal Conjugation. Bioconj. Chem. 2011, 22, 2263-2270.

(83) Blackman, M. L.; Royzen, M.; Fox, J. M. Tetrazine ligation: Fast bioconjugation based on inverse-electron-demand Diels-Alder reactivity. J. Am. Chem. Soc. 2008, 130, 13518-+.

(84) Pigga, J. E.; Rosenberger, J. E.; Jemas, A.; Boyd, S. J.; Dmitrenko, O.; Xie, Y.; Fox, J. M. General, Divergent Platform for Diastereoselective Synthesis of trans-Cyclooctenes with High Reactivity and Favorable Physiochemical Properties**. Angew. Chem. Int. Ed. Engl. 2021, 60, 1497514980.

(85) Lambert, W. D.; Scinto, S. L.; Dmitrenko, O.; Boyd, S. J.; Magboo, R.; Mehl, R. A.; Chin, J. W.; Fox, J. M.; Wallace, S. Computationally guided discovery of a reactive, hydrophilic trans5-oxocene dienophile for bioorthogonal labeling. Org. Biomol. Chem. 2017, 15, 6640-6644.

(86) Taylor, M. T.; Blackman, M. L.; Dmitrenko, O.; Fox, J. M. Design and synthesis of highly reactive dienophiles for the tetrazine-trans-cyclooctene ligation. J. Am. Chem. Soc. 2011, 133, 9646-9649.

(87) Romero, N. A.; Nicewicz, D. A. Organic Photoredox Catalysis. Chem. Rev. 2016, 116, $10075-10166$.

(88) Wang, H.; Li, W.-G.; Zeng, K.; Wu, Y.-J.; Zhang, Y.; Xu, T.-L.; Chen, Y. Photocatalysis Enables Visible-Light Uncaging of Bioactive Molecules in Live Cells. Angew. Chem. Int. Ed. Engl. 2019, 58, 561-565.

(89) Pompella, A.; Visvikis, A.; Paolicchi, A.; Tata, V. D.; Casini, A. F. The changing faces of glutathione, a cellular protagonist. Biochem. Pharmacology 2003, 66, 1499-1503.

(90) Hannesschlaeger, C.; Pohl, P. Membrane Permeabilities of Ascorbic Acid and Ascorbate. Biomolecules 2018, 8.

(91) Umlauf, B. J.; Mix, K. A.; Grosskopf, V. A.; Raines, R. T.; Shusta, E. V. Site-Specific Antibody Functionalization Using Tetrazine-Styrene Cycloaddition. Bioconjugate chemistry 2018, 29, 1605-1613.

(92) Jang, H. S.; Jana, S.; Blizzard, R. J.; Meeuwsen, J. C.; Mehl, R. A. Access to Faster Eukaryotic Cell Labeling with Encoded Tetrazine Amino Acids. J. Am. Chem. Soc. 2020, 142, 72457249.

(93) Blizzard, R. J.; Backus, D. R.; Brown, W.; Bazewicz, C. G.; Li, Y.; Mehl, R. A. Ideal Bioorthogonal Reactions Using A Site-Specifically Encoded Tetrazine Amino Acid. J. Am. Chem. Soc. 2015, 137, 10044-10047.

(94) Blankman, J. L.; Cravatt, B. F. Chemical probes of endocannabinoid metabolism. Pharmacological Rev. 2013, 65, 849-871.

(95) Kohrt, J. T.; Dorff, P. H.; Burns, M.; Lee, C.; O’Neil, S. V.; Maguire, R. J.; Kumar, R.; Wagenaar, M.; Price, L.; Lall, M. S. Application of Flow and Biocatalytic Transaminase Technology for the Synthesis of a 1-Oxa-8-azaspiro[4.5]decan-3-amine. Org. Proc. Res. Dev. 2021. 
(96) Chang, J. W.; Niphakis, M. J.; Lum, K. M.; Cognetta, A. B., 3rd; Wang, C.; Matthews, M. L.; Niessen, S.; Buczynski, M. W.; Parsons, L. H.; Cravatt, B. F. Highly selective inhibitors of monoacylglycerol lipase bearing a reactive group that is bioisosteric with endocannabinoid substrates. Chem. Biol. 2012, 19, 579-588.

(97) Butler, C. R.; Beck, E. M.; Harris, A.; Huang, Z.; McAllister, L. A.; Am Ende, C. W.; Fennell, K.; Foley, T. L.; Fonseca, K.; Hawrylik, S. J.; Johnson, D. S.; Knafels, J. D.; Mente, S.; Noell, G. S.; Pandit, J.; Phillips, T. B.; Piro, J. R.; Rogers, B. N.; Samad, T. A.; Wang, J.; Wan, S.; Brodney, M. A. Azetidine and Piperidine Carbamates as Efficient, Covalent Inhibitors of Monoacylglycerol Lipase. J. Med. Chem. 2017, 60, 9860-9873.

(98) Chang, J. W.; Cognetta, A. B., 3rd; Niphakis, M. J.; Cravatt, B. F. Proteome-wide reactivity profiling identifies diverse carbamate chemotypes tuned for serine hydrolase inhibition. ACS Chem. Biol. 2013, 8, 1590-1599.

(99) Fish, K. N. Total internal reflection fluorescence (TIRF) microscopy. Curr. Protocols in cytometry 2009, Chapter 12, Unit12.18-Unit12.18. 